\title{
Trade liberalization and markups: Micro evidence from China*
}

\author{
Haichao $\operatorname{Fan}^{a} \quad$ Xiang $\mathrm{Gao}^{b \dagger} \quad$ Yao Amber $\mathrm{Li}^{c} \quad$ Tuan Anh Luong ${ }^{d}$ \\ ${ }^{a}$ Institute of World Economy, School of Economics, Fudan University, China \\ ${ }^{b}$ School of International Business Administration, Shanghai University of Finance and \\ Economics, China \\ ${ }^{c}$ Department of Economics and Faculty Associate of the IEMS, Hong Kong University \\ of Science and Technology, China \\ ${ }^{d}$ Faculty of Business and Law, De Montfort University, U.K.
}

This Version: November 25, 2016

\begin{abstract}
This paper presents evidence from highly disaggregated Chinese firm-product data that, given productivity, input tariff reductions induce an incumbent importer/exporter to increase product markups. We further investigate empirically the mechanisms underlying this trade liberalization effect, and find that input tariff reductions decrease marginal costs, and their effects on markup adjustments are more profound among firms with higher import dependence. Moreover, we exploit unique features of Chinese data by comparing results for two trade regimes: ordinary trade (wherein firms pay import tariffs to import) and processing trade (wherein firms are not subject to import tariffs). While the aforementioned trade liberalization effects and mechanisms only apply to ordinary trade, processing trade samples are used in a placebo test. The paper also shows that more productive firms charge higher markups for products. All these findings are robust to alternative markup measures including one estimate using physical-quantity output data, different production function specifications, a subsample consisting only of pure exporters, and estimations based on our theoretical derivations.
\end{abstract}

Keywords: Tariff reduction; Markup; Marginal cost; Ordinary trade JEL: F1, F4, O4

*We thank Frederic Warzynski, Meredith Crowley, Kyle Handley, Jota Ishikawa, Larry Qiu, Miaojie $\mathrm{Yu}$, and two anonymous referees for helpful comments. We acknowledge the financial support from the Natural Science Foundation of China (No.71501117; No.71603155), the Shanghai Pujiang Program (No.15PJC041; No.12PJC048), the Research Grants Council of Hong Kong, China (General Research Funds and Early Career Scheme GRF/ECS Project No.646112), and the self-supporting project of Institute of World Economy at Fudan University. All remaining errors are our own.

†Corresponding author. Fax: +86 216590 7458. E-mail addresses: gao.xiang@shufe.edu.cn (X. Gao), fan_haichao@fudan.edu.cn (H. Fan), yaoli@ust.hk (Y. A. Li), tuan.luong@dmu.ac.uk (T. A. Luong). 


\section{Introduction}

Globalization has been one of the centers of economic research. It is usually characterized by openness to final foreign goods and the accompanying competition effect. However, transactions of intermediate inputs have become increasingly important in global trade (see Johnson and Noguera, 2012; Koopman, Wang and Wei, 2014). This trend now prompts economists to switch their attention to input trade liberalization (e.g., Amiti and Konings, 2007; Bas, 2012).

A typical trade model would assume a constant elasticity of substitution (CES) utility function due to its tractability. One implication of this type of model is that firms charge a constant markup on their products. However, this implication is unsatisfactory since, as shown by Simonovska (2015), variable markup is the main reason why export prices respond to variations in a destination country's income. Policy makers would be interested to know the degree of market competitiveness, indicated by changes in markups, when they analyze merger and acquisition proposals or design industry competition policies. A welfare evaluation analysis would also involve understanding the distribution of markups (Edmond, Midrigan and Xu, 2015).

This paper contributes to the literature by examining whether lower tariffs on imported intermediates can cause firms to adjust firm-product markups for exported goods, and by determining the direction and size of such adjustments. ${ }^{1}$ To meet the requirements upon accession to the World Trade Organization (WTO) in December of 2001, China has significantly decreased its tariffs imposed on imported goods; in particular, the average input tariff dropped by approximately $40 \%$ from 2000 to 2006. Meanwhile, Chinese export tariffs did not change much after joining the WTO, as China has long enjoyed most-favored-nation treatment from its major trading partners. This difference results in arguably unilateral trade liberalization in China (Fan, Li and Yeaple, 2015), which serves as a quasi-natural trade reform for estimating the effect of import tariff reductions on firms' market powers.

The use of Chinese data is also advantageous given its distinction between two trade regimes: ordinary trade (wherein firms pay import tariffs to import) and processing trade (wherein firms are not subject to import tariffs). More than $50 \%$ of transactions carried out in Chinese trade involve processing trade mechanisms, thus uniquely enabling us to identify the specific effect of trade liberalization (via input tariff reductions) on firms' markup adjustments. When we examine the input-tariff effects on ordinary firms' markups, processing trade observations may be used as a placebo sample since such

\footnotetext{
${ }^{1}$ In robustness checks, we also study the responses of firm-level markups, which measure firm competitiveness in both domestic and foreign markets. Nevertheless, our focus in this paper is on firm-product markup since highly disaggregate data on the firm-product level allows us to clearly distinguish between two different trade regimes.
} 
effects are supposed to be absent for processing trade firms who are exempt from import tariffs. To be consistent with the firm-product transaction-level customs dataset that distinguishes between ordinary and processing trade regimes, we match production data with customs data and use the merged sample to estimate firm-product markups following an augmented approach by De Loecker et al. (2016). ${ }^{2}$

To begin with, we document two stylized facts regarding the relationship between China's trade liberalization upon WTO accession and firm-product markup adjustments by incumbent Chinese exporters. Specifically, we find that (1) China's trade liberalization is largely driven by firms' improved access to imported intermediate inputs, and (2) ordinary trade firms raise their markup levels in response to input tariff reductions, while processing trade firms do not.

We then substantiate these patterns in a simple model with heterogeneous firms and variable markups. The prediction is that, when productivity is controlled for, a reduction in import tariffs enables an ordinary trade firm to become more efficient by making cheaper and superior inputs accessible to them. Furthermore, the theory predicts that a more efficient ordinary trade firm charges higher markups. However, these results do not apply to processing trade, a typical practice that pays no import tariffs in China. Hence, a processing trade firm would not enjoy a similar reduction in marginal costs.

Consistent with our theoretical predictions, a comprehensive empirical analysis confirms that ordinary trade observations significantly respond to tariff reductions by increasing their markups while processing trade observations do not. Next, we explore the validity of marginal cost effects and import dependence levels as the underlying mechanisms in our theoretical model, and analyze the effect of input tariff reductions on export movements. Our empirical results are robust to various estimation specifications and different markup measures at both firm-product and firm level. More precisely, we validate our empirical results with markup measures that rely on an alternative form of production function, a pool of pure exporters, and an estimation procedure derived from our own model that requires only observable market shares and substitution elasticities. In addition, to show that our empirical results are robust to both revenue-based and quantity-based production function estimates, we employ a new dataset obtained from the National Bureau of Statistics of China (NBSC) that contains information on the physical quantities of our sample firms' output.

This paper is related to a growing literature on how trade liberalization can lead

\footnotetext{
${ }^{2}$ The firm-level production dataset does not make a distinction between processing trade and ordinary trade. However, the firm-product customs dataset is rich enough to provide trade regime information at the transaction level. If we define processing or ordinary trade at the firm level, then more than $40 \%$ of firms are hybrids that conduct both processing and ordinary trade transactions. Therefore, it is preferable to use firm-product markup instead of firm markup in the context of differentiating between processing and ordinary trade regimes.
} 
to efficient allocation of resources among firms (e.g., De Loecker et al., 2016; Arkolakis et al., 2015). As noted in De Loecker et al. (2016), many previous studies in this field have only examined the competitive effects caused by output tariff reductions, whereas the implications of input tariff reductions have attracted less effort.

Our paper is complementary to previous research that analyzed the impact of trade liberalization on firms' market powers. In contrast to their focus on the developed world (Chen, Imbs and Scott, 2009; Konings, Van Cayseele and Warzynski, 2001), we direct our attention towards emerging markets and developing countries. Although we are not the first to make these cases, for example, Harrison, 1994 examined the case of Côte d'Ivoire, Levinsohn, 1993 the case of Turkey, and De Loecker et al. (2016) the case of India, we differ from their studies in approaching the issue through a rather unique feature of Chinese data: the presence of the processing trade regime as the control group in identifying the operation mechanism of tariff reductions.

Our paper is also complementary to a large body of literature that emphasizes the role of accessibility to imported intermediates in improving firm performance. This research group considers positive markup adjustment as one novel dimension of firm response to achieve superior performance. ${ }^{3}$

Finally, we indirectly contribute to an ongoing discussion of transforming policy to welfare outcomes. Since our findings suggest that more import dependent firms set higher markups during input market liberalization, there would be an adjustment of markup distribution across the industry. In a recent paper, Edmond, Midrigan and Xu, 2015 concludes that the distribution of markup is an important determinant of social welfare. Therefore, our paper links a particular type of trade policy to welfare implications. We also contribute to a nascent literature that explores the difference between ordinary and processing trade firms' behaviors (see Yu, 2015; Manova and Yu, forthcoming).

The rest of the paper is organized as follows. Section 2 documents two stylized facts regarding trade liberalization and markup adjustment. Section 3 presents a simplified theory to examine the impact of tariff reductions on firms' markups. Section 4 describes the identification strategy, datasets, and measurements used, as well as the estimation method for firm-product markups. Section 5 presents our econometric specifications and reports the main results, followed by an interpretation of the underlying mechanisms. Section 6 conducts a variety of robustness checks, and the final section is the conclusion.

\footnotetext{
${ }^{3}$ Traditional dimensions of superior firm performance include improved total factor productivity (e.g., Amiti and Konings, 2007; Yu, 2015; Halpern, Koren and Szeidl, 2015; Gopinath and Neiman, 2014), quality upgrading (e.g., Amiti and Khandelwal, 2013; Fan, Li and Yeaple, 2015; Fan, Li and Yeaple, 2016; Bas and Strauss-Kahn, 2015), and expanded product scope (e.g., Goldberg et al., 2010).
} 


\section{Stylized facts}

This section documents two stylized facts concerning the relationship between China's trade liberalization and Chinese exporting firms' markup. The method used to estimate firm-product markups is described in great detail in Section 4. Note that we categorize goods under the HS6 product classification.

Figure 1: China's Import Values 2000-2006 (Aggregated by Category, in Trillion U.S. Dollars)

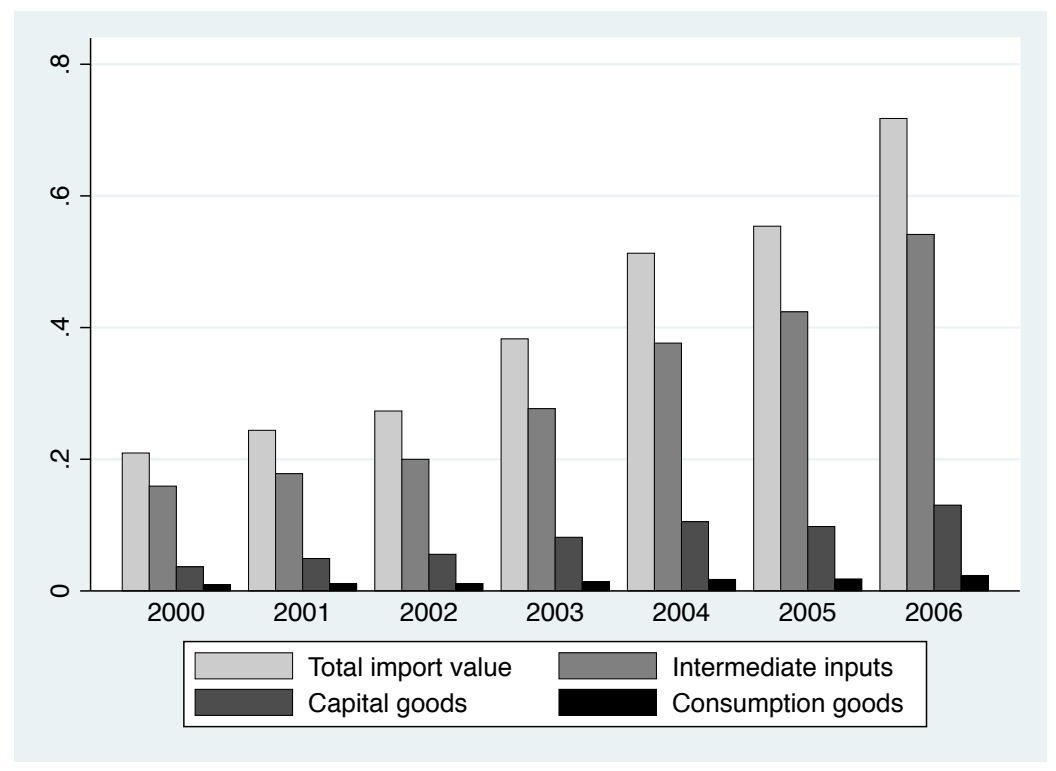

Notes: Import values are computed for the entire Customs dataset. This figure does not distinguish between ordinary trade and processing trade. The illustration for ordinary trade alone displays a similar pattern and is available upon request.

It is widely recognized that China has carried out substantial liberalization reform since joining the WTO in 2001, and trade openness has significantly affected its final and intermediate goods markets. According to the Bureau of Economic Analysis (BEA) classification, we use the entire universe of the Chinese customs database to plot a bar chart for both aggregate and component (capital goods, intermediate goods, and final consumption goods) values of Chinese imports in Figure 1. As can been seen from the Figure, aggregate imports by Chinese firms have more than tripled from 0.21 trillion U.S. dollars in 2000 to 0.72 trillion U.S. dollars in 2006. More importantly, the majority of Chinese imports are intermediate $(74 \%)$ and capital goods (19\%). Imported final goods only account for $4 \%$ of total imports and this small share has remained fairly stable overtime. ${ }^{4}$ This determines our first stylized fact:

\footnotetext{
${ }^{4} \mathrm{~A}$ fourth "uncertain" category represents the remaining $3 \%$ of total import value.
} 
Stylized fact 1 . Trade liberalization in China since its accession to the WTO has largely been driven by improved access to imported intermediate inputs.

Figure 1 presents evidence that much of the rise in total imports stems from a surge in intermediate and capital goods, both of which can be broadly referred to as inputs. As a result, China serves as an appropriate research object to examine the impacts of trade liberalization (in the form of input tariff reductions) on firms' market powers (for which we use markups to proxy).

To visualize changes in Chinese firms' market powers, we first estimate firm-product markups using a version of De Loecker et al. (2016)'s methodology that is slightly modified to accommodate unique characteristics of the Chinese data. This method was designed to examine multi-product firms' pricing strategies, so it has the flexibility to assign different markups to different products. Before moving to the next step, we have to mention that the markup estimation uses a sample of manufacturing firms derived from merging production data with customs data (see Section 4 for a detailed description).

Figure 2: Markup Adjustments and Input Tariff Cuts (Ordinary Trade vs. Processing Trade)

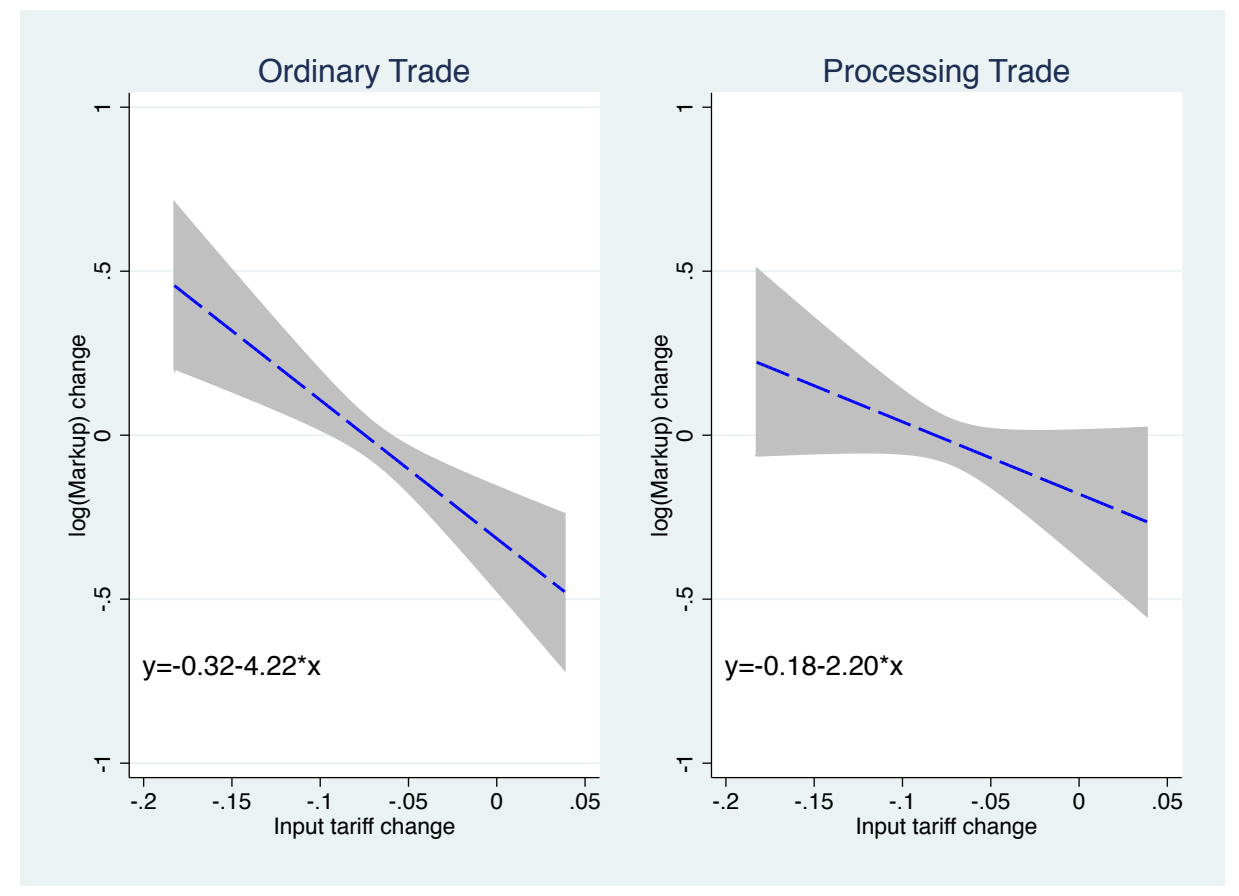

Notes: The dashed lines represent fitted values from regressing changes in firm-product markups on input tariff changes. The shaded areas represent associated confidence intervals. The amount of variable changes equals to that variable's value in 2006 minus its value in 2000 .

Input tariffs are calculated by combining product-level output tariffs and China's input-output (IO) table (see Section 4 for the computation process). We then regress change in markup estimates between the years 2000 and 2006 on change in input tariffs 
over the same period, and plot in Figure 2 the predicted markup adjustments within a $90 \%$ confidence interval against input tariff cuts for each of the two trade regimes. We find that the size of tariff effects on markup adjustments depends on whether the ordinary or processing trade regime is considered. For ordinary trade firms, input tariff reductions increase their markups significantly (i.e., firms facing larger cuts in tariffs raise markups to higher degrees); for processing trade firms, this relationship is much less pronounced. This phenomenon can be attributed to the fact that processing trade firms are exempt from input tariffs, and can only enjoy an indirect benefit if they cooperate with ordinary trade suppliers domestically. We thus summarize the second stylized fact as follows:

Stylized fact 2. In response to input tariff reductions during trade liberalization, an ordinary trade firm raises its markups to a large extent, while a processing trade firm does not make such significant adjustments.

\section{A simple model}

In this section, we present a bare-bones, partial equilibrium model of trade with heterogeneous firms. The aim is to provide a theoretical explanation of how import tariff reductions can induce incumbent import/export firms to adjust their markups as well as marginal costs. In the model, for each domestic firm, final goods production involves an intermediate inputs bundle that contains both domestically supplied and foreign-imported intermediate inputs.

\subsection{Consumers}

The preference of a representative consumer is given by a CES utility function defined over a discrete variety of final goods indexed by $\omega$ :

$$
U=\left[\sum_{\omega} x(\omega)^{\frac{\sigma-1}{\sigma}}\right]^{\frac{\sigma}{\sigma-1}}
$$

where $x(\omega)$ is the quantity demanded for good $\omega$. All goods are substitutes for each other with an elasticity of substitution $\sigma>1$. The representative consumer's optimization problem then yields the optimal demand for good $\omega$, which satisfies:

$$
x(\omega)=\frac{p(\omega)^{-\sigma}}{P^{1-\sigma}} E
$$

where $p(\omega)$ is the unit price of good $\omega, P=\left[\sum_{\omega} p(\omega)^{1-\sigma}\right]^{\frac{1}{1-\sigma}}$ is the price index for a basket of goods, and $E$ is the aggregate consumption expenditure. 


\subsection{Producers}

Production.-We assume there are a countable finite number of varieties, each produced by a single incumbent firm in the industry. Each firm is also allowed to produce multiple products. Specifically, variety $\omega$ is produced by a firm with productivity $\varphi$ according to the following production function:

$$
Y=\exp (\varphi)\left(K^{a} L^{1-a}\right)^{1-\eta} Z^{\eta}
$$

where $K$ and $L$ respectively denote capital and labor inputs employed, and $Z$ denotes the intermediate inputs bundle employed in final variety production. The intermediates bundle $Z$ is assembled by combining one bundle of continuum intermediate inputs produced domestically, $D$, and another bundle of diverse intermediate inputs imported globally, $M$, according to the following CES aggregator:

$$
Z=\left(D^{\frac{\varsigma-1}{\varsigma}}+M^{\frac{\varsigma-1}{\varsigma}}\right)^{\frac{\varsigma}{\varsigma-1}}
$$

where $\varsigma$ is the elasticity of substitution between the domestic and foreign bundles of inputs. These component input bundles themselves are also CES aggregates:

$$
\begin{aligned}
D & =\left(\int_{0}^{1} d(l)^{\frac{\theta-1}{\theta}} d l\right)^{\frac{\theta}{\theta-1}}, \\
M & =\left(\int_{\Omega} m(h)^{\frac{\theta-1}{\theta}} d h\right)^{\frac{\theta}{\theta-1}}
\end{aligned}
$$

where $d(l)$ represents the firm's use of a domestic input $l$, and $m(h)$ represents the quantity of a foreign input $h$ imported by that firm. $\Omega$ is a firm-specific constant set containing all imported input varieties. ${ }^{5}$ The elasticity of substitution among domestic inputs and the elasticity of substitution among foreign inputs are assumed to be identical and denoted by $\theta>1{ }^{6}$

Import Decision.-Conditional on being an importer, the decisions a firm then needs to make are which varieties to import and how much of each variety to import. To simplify the derivation, we assume that the scope decision is exogenously given, and hence the set of imported varieties for a firm is fixed. ${ }^{7}$

\footnotetext{
${ }^{5}$ We assume no fixed costs for importing exists.

${ }^{6}$ Alternatively, we can assign different $\theta$ 's to inputs within domestic varieties and to those within foreign varieties. However, the propositions would be preserved.

${ }^{7}$ If we allow this set to vary endogenously, an input tariff reduction would induce the firm to import more varieties if assumptions are made as in Gopinath and Neiman (2014). Enlarging the set of imported varieties would further decrease marginal costs and increase markups.
} 
The firm chooses labor $L$, capital $K$, and the amounts of domestic intermediate inputs $d(l)$, given the wage rate $w$, the rental rate $r$, and the prices of domestic intermediate inputs $p(l)$. The firm also chooses the amount of each imported variety $m(h)$, given each foreign input's price $p(h)$ and the import tariff $\tau(h)$ levied on each imported product $h$. Given the above production function and the firm's productivity $\varphi$, the marginal cost of inputs when producing the final good $\omega$ satisfies:

$$
c(\omega)=\frac{B^{\eta}}{\exp (\varphi)} \frac{P_{V}^{1-\eta} P_{Z}^{\eta}}{\eta^{\eta}(1-\eta)^{1-\eta}}
$$

where $P_{V}=\frac{r^{a} w^{1-a}}{a^{a}(1-a)^{1-a}}$ is the price index for capital and labor, and $P_{Z}=\left(\int_{0}^{1} p(l)^{1-\theta} d l\right)^{\frac{1}{1-\theta}}$ is the price index for domestic inputs. Therefore, $\frac{P_{V}^{1-\eta} P_{Z}^{\eta}}{\eta^{\eta}(1-\eta)^{1-\eta}}$ denotes the marginal cost index for a non-importing firm. To derive the marginal cost index for an importing firm, we need to multiply the non-importer's marginal cost index by an additional cost-reduction factor $B \equiv\left(1+\left(P_{M} / P_{Z}\right)^{1-\varsigma}\right)^{\frac{1}{1-\varsigma}}$, where $P_{M}$ is the price index for imported inputs:

$$
P_{M}=\left(\int_{\Omega}(\tau(h) p(h))^{1-\theta} d h\right)^{\frac{1}{1-\theta}}
$$

\subsection{Firm's behavior}

Given the demand equation (1), the profit maximization problem of a product $\omega$ produced by a firm with productivity $\varphi$ is given by:

$$
\max _{p(\omega)}(p(\omega)-c(\omega)) \frac{p(\omega)^{-\sigma}}{\sum_{\omega} p(\omega)^{1-\sigma}} E
$$

Since the number of final-good varieties is finite, a change in $p(\omega)$ will affect the price index $P$. Taking the first-order condition with respect to $p(\omega)$ implies that:

$$
1-\sigma \frac{(p(\omega)-c(\omega))}{p(\omega)}+(\sigma-1) \frac{(p(\omega)-c(\omega))}{p(\omega)} \frac{p(\omega)^{1-\sigma}}{\sum_{\omega} p(\omega)^{1-\sigma}}=0
$$

where

$$
\frac{p(\omega)^{-\sigma}}{\sum_{\omega} p(\omega)^{1-\sigma}}=s(\omega)
$$

is the market share of final good $\omega$. Reorganizing the first-order condition (8), we have: 


$$
p(\omega)=c(\omega)\left(1+\frac{1}{(\sigma-1)(1-s(\omega))}\right)
$$

We use $\mu(\omega)=\ln \left(\frac{p(\omega)}{c(\omega)}\right)$ to denote the markup charged by a firm with productivity $\varphi$ for its final good $\omega$. The previous equation (10) implies that the firm-product markup:

$$
\mu(\omega)=\ln \left(1+\frac{1}{(\sigma-1)(1-s(\omega))}\right)
$$

is clearly an increasing function of good $\omega$ 's market share $s(\omega)$.

Taking the total differentiation of the firm-product markup function, we obtain:

$$
\begin{gathered}
\Delta \ln \mu(\omega)=\Gamma(\omega) \Delta \ln s(\omega)=-(\sigma-1) \Gamma(\omega)(1-s(\omega)) \Delta \ln p(\omega) \\
=-(\sigma-1) \Gamma(\omega)(1-s(\omega))(\Delta \ln \mu(\omega)+\Delta \ln c(\omega))
\end{gathered}
$$

where $\Gamma(\omega)=\frac{s(\omega)}{1-s(\omega)} \frac{1}{(\sigma-1)(1-s(\omega))+1}>0$. Hence, the change in markup can be written as a function of the change in marginal costs:

$$
\Delta \ln \mu(\omega)=-\frac{(\sigma-1) \Gamma(\omega)(1-s(\omega))}{1+(\sigma-1) \Gamma(\omega)(1-s(\omega))} \Delta \ln c(\omega)
$$

As a result, the firm-product markup is decreasing with the firm-product marginal cost. According to equation (6), a high-productivity firm would have low marginal costs and hence set high markups. This is summarized by the following proposition:

Proposition 1. A more efficient firm charges higher markups.

During trade liberalization, a reduction in import tariff $\tau_{h}$ leads to a fall in the price index of imported inputs, $P_{M}$, and hence a decrease in the cost-reduction factor $B$. Equation (6) then implies that the marginal cost $c$ also falls accordingly. Based on equation (12), we have the following proposition:

Proposition 2. Given productivity, a reduction in import input tariffs induces a firm to charge a higher markup for its output products.

This proposition applies to the firm's whole line of products in general, and in particular, to the firm's exported products. Since our focus is on incumbent importers and exporters, we will test the above proposition using exported products in the empirical part of this paper. The empirical results derived from Chinese trade data turn out to support our theoretical claims, that is, trade liberalization can indeed induce firms to charge higher markups for their exports, even after we control for variations in productivity. 


\section{Identification and measurement}

In this section, we first present our identification strategy, which takes advantage of the differences between ordinary and processing trade. Note that processing trade firms are exempted from paying import tariffs. Thus they serve as a natural comparison group to identify the causal relationship between tariff reductions and markup adjustments at the firm-product level. We then describe the data sample and measurements used in our empirical analysis.

\subsection{Identification strategy: ordinary trade vs. processing trade}

Processing trade is very common in Chinese trading firms (Yu, 2015; Manova and Yu, forthcoming). It can exist in one of two forms in customs documents: "processing with supplied inputs" and "processing with imported inputs." The former refers to the situation in which a Chinese firm receives inputs from its trading partners, assembles them into final goods, and directly exports these goods back to the same trading partners. The latter refers to the situation in which a Chinese firm pays for imported inputs from foreign suppliers, and exports all processed goods with no intent to sell domestically. Both types of processing trade firms enjoy duty-free treatment. In the presence of processing trade, a firm falls into one of the following three categories: a non-importing firm, an ordinary importer, or a processing importer. As processing trade firms are not subject to import tariffs, our expectation is that the marginal cost effect does not apply to them.

To identify the causal effects of tariff reductions on markup adjustments, we compare the responses by ordinary and processing firms to tariff cuts, and the unique Chinese data allows us to do so. Note that trade types are identified at the firm-product level instead of at the firm level. This is because a sizable portion of firms, also called hybrid firms, may conduct both ordinary and processing trade for their various products. At the firm level, pure ordinary firms, pure processing firms, and hybrid firms account for $36.31 \%$, $23.20 \%$, and $40.49 \%$ of total trade, respectively. Defining ordinary and processing trade at the firm-product level thus allows us to clearly distinguish between the two trade regimes according to customs records. Moreover, this definition is in congruence with the estimated firm-product markups. ${ }^{8}$

\footnotetext{
${ }^{8}$ It is possible that a firm-HS6-product pair still involves both processing and ordinary trade since exports can be directed to different destinations. But the proportion of this kind of "hybrid" firm-product only accounts for $9.31 \%$ of total trade in our sample.
} 


\subsection{Firm-product trade data and firm-level production data}

With regard to the estimation of firm-product markups, on the one hand, we need to rely on product-level trade data to obtain export prices, export values, and trade regimes; on the other hand, we must use firm-level production data to measure firm attributes (e.g., TFP). Therefore, before we can proceed, merging the following two databases is required: (1) a firm-product-level trade database that records each transaction through Chinese customs, and (2) a firm-level production database collected and maintained by the NBSC. Our sample period runs from 2000 to $2006 .^{9}$

Firm-product-level trade data.- The customs' transaction-level trade data is from China's General Administration of Customs. This database provides information on HS8 product characteristics, covering the universe of all Chinese imports and exports during 2000 to 2006. It records all details for each trade transaction, including import or export values, quantities, products, source and destination countries, firm contacts (e.g., company name, telephone, zip code, and contact person), enterprise types (e.g., state owned, domestic private, foreign invested, or joint venture), and customs regimes (e.g., "Processing and Assembling" or "Processing with Imported Materials"). As processing trade firms pay no tariffs, we focus on ordinary trade firms and use processing trade firms as a placebo test sample. We aggregate transaction-level trade data to the firm-product level. To ensure the consistency of product categorizations over time, we aggregate HS8 products to the HS6 level. ${ }^{10}$ Therefore, a product in this paper refers to an HS6 product category. Also, note that we focus only on manufacturing products in this database to maintain consistency. ${ }^{11}$

Firm-level production data.-To characterize firm characteristics (e.g., TFP and capital intensity), we use NBSC firm-level production data drawn from annual surveys sent to all state-owned enterprises (SOEs) and non-state-owned enterprises with annual sales larger than 5 million RMB (Chinese currency). This NBSC database contains detailed firm-level information on Chinese manufacturers, including employment, capital stock, gross output, value added, and firm contacts, similar to the Customs database. ${ }^{12}$ Considering the case of misreports, we remove unsatisfactory observations according to the

\footnotetext{
${ }^{9}$ In robustness checks, we employ a third database that is also taken from the NBSC and contains physical-quantity output information for single-product firms. The goal is to resolve doubt about the problem of omitted firm-specific prices, which occurs when revenue-based measures are used to estimate TFP and markups (see Section 6 for more explanations).

${ }^{10}$ At the HS8 level, although the first six digits of HS-codes follow international standards, Chinese customs' officials frequently change the last two digits. Hence, we convert 2002 HS-codes into 1996 HS-codes at the six-digit HS level based on UN Comtrade specifications.

${ }^{11}$ Originally, there were 20 sectors included in the UN list of HS product classifications (see http://unstats.un.org/unsd/tradekb/Knowledgebase/HS-Classification-by-Section). We omit sectors 1 to 3 (agricultural sectors), sector 5 (the mining sector), and sector 19 (arms and ammunition).

${ }^{12}$ This information on firm identity is what we used to match the NBSC database with the customs database.
} 
following protocols: (i) total assets must be higher than liquid assets; (ii) total assets must be higher than total fixed assets; (iii) total assets must be higher than the net value of fixed assets; (iv) the firm identification number cannot be missing and must be unique; and $(\mathrm{v})$ the established time must be valid. These protocols are in accordance with Cai and Liu (2009) and General Accepted Accounting Principles.

Matching the two databases.-Finally, we are ready to match the customs trade data with the NBSC production data. The match is based on common entries found in the two databases: various contacts of manufacturing firms, as there exists no consistent coding system on firm identity for them. Our matching procedure is carried out in three steps: (1) by company name, (2) by telephone number and zip code, and (3) by telephone number and contact person name (see a detailed description of the matching process in Fan, Lai and Li, 2015). Compared to exporting and importing firms reported in the customs database, ${ }^{13}$, the matching rate of our merged sample (in terms of the number of firms) covers $45.3 \%$ of all exporters and $40.2 \%$ of all importers. Respectively, these correspond to $52.4 \%$ of total export values and $42 \%$ of total import values reported by the customs database. ${ }^{14}$

\subsection{Measure of firm-product markup}

This section describes the construction process of measures for firm-product markups. As shown by De Loecker et al. (2016), the markup for product $h$ produced by firm $f$ at time $t$ can be expressed as (see Appendix A for derivations):

$$
\mu_{f h t}=\ln \left(\theta_{f h t}^{v}\left(\alpha_{f h t}^{v}\right)^{-1}\right)
$$

where $\theta_{f h t}^{v}$ denotes the output elasticity on variable input $V_{f h t}^{v}$, and $\alpha_{f h t}^{v}=\frac{P_{f h t}^{v} V_{f h t}^{v}}{P_{f h t} Q_{f h t}}$ is the share of output revenue spent on inputs for product $h$ produced by firm $f$ at time $t$ : the denominator $P_{f h t} Q_{f h t}$ represents firm $f$ 's total revenue earned from selling product $h$ at time $t$, and the numerator $P_{f h t}^{v} V_{f h t}^{v}$ represents firm $f$ 's expenditure on input $V_{f h t}^{v}$.

Equation (13) lays down the foundation for our estimation. To compute the markup, we need to know the output elasticity $\theta_{f h t}^{v}$ and the ratio of input expenditure to total sales $\alpha_{f h t}^{v}$. First of all, consider the following translog production function:

$$
q_{f h t}=f\left(x_{f h t} ; \beta\right)+\varphi_{f t}+\epsilon_{f h t}
$$

\footnotetext{
${ }^{13}$ When we merge the customs database with manufacturing firms listed in the NBSC database, we exclude observations labeled as intermediary firms and trading companies by Chinese customs.

${ }^{14}$ We do not compare the size of our merged sample to that of the NBSC database because the NBSC data does not indicate a firm's import status.
} 
where lowercase letters denote the log of uppercase letters. ${ }^{15}$ The quantity of product $h$ by firm $f$ at time $t, q_{f h t}$, is produced using a set of firm-product-year specific inputs, $x_{f h t}$. The error term $\epsilon_{f h t}$ captures measurement errors in recording output values and any unanticipated shocks to output. Following De Loecker et al. (2016), the productivity term $\varphi_{f t}$ is assumed to be Hicks-neutral and firm-specific.

For multi-product firms, due to data limitations, it is difficult to determine how inputs are allocated across different products within a firm. Let us denote the log of input $X$ 's share in producing $h$ as $\rho_{f h t}^{X}=x_{f h t}-x_{f t}$. In this equation, $x_{f t}$ is the observable total input expenditure by firm $f . x_{f h t}$ is the non-observable input expenditure allocated to product $h$ for any input $X=\{L, M, K\}$, where $L, M$, and $K$ respectively denote labor, materials, and capital. Substituting this expression in equation (14) yields:

$$
q_{f h t}=f\left(x_{f t} ; \beta\right)+\varphi_{f t}+A_{f h t}\left(\rho_{f h t}^{X} ; x_{f t} ; \beta\right)+\epsilon_{f h t}
$$

Since we do not observe multi-product firms' input allocation across products, the production function (15) contains an extra error term, $A_{f h t}(\cdot)$, when compared to the previous equation (14). In general, this component error will be a function of three arguments: the unobserved input shares $\rho_{f h t}^{X}$, the firm-level input expenditure $x_{f t}$, and the production function coefficients $\beta$. In the case of a translog production function, the $\log$ input $x_{f t}$ is a vector containing labor, materials, and capital as well as all second-order interaction terms between any two among them; the vector of coefficients can be written as $\beta=\left(\beta_{l}, \beta_{m}, \beta_{k}, \beta_{l l}, \beta_{m m}, \beta_{k k}, \beta_{l m}, \beta_{l k}, \beta_{m k}\right) .{ }^{16}$ Based on the methodology in De Loecker and Warzynski (2012) and De Loecker et al. (2016), we use the firm-level production survey data from the NBSC to estimate the set of coefficients, $\beta$, in the production function $q_{f t}=f\left(x_{f t} ; \beta\right)+\varphi_{f t}+\epsilon_{f t}$ (see Appendix B for more details). ${ }^{17}$

Let $\rho_{f h t}=\ln \left(\frac{\widetilde{X}_{f h t}}{\widetilde{X}_{f t}}\right)$ be the input cost share of product $h$, where $\widetilde{X}_{f t}$ denotes total deflated expenditures on all inputs used by firm $f$ at time $t$. We assume that $\rho_{f h t}$ does not vary across inputs so that we can solve for this share as follows. In order to eliminate unanticipated shocks and measurement errors that are present in the output data, we

\footnotetext{
${ }^{15}$ A general expression for this translog production function with labor, capital, and material as input factors would be $q_{f h t}=\beta_{l} l_{f h t}+\beta_{m} m_{f h t}+\beta_{k} k_{f h t}+\beta_{l l} l_{f h t}^{2}+\beta_{m m} m_{f h t}^{2}+\beta_{k k} k_{f h t}^{2}+\beta_{l m} l_{f h t} m_{f h t}+$ $\beta_{m k} m_{f h t} k_{f h t}+\beta_{k l} k_{f h t} l_{f h t}+\varphi_{f t}+\epsilon_{f h t}$.

${ }^{16}$ In Section 5.3 and 6.1 , as a robustness check, we also use an alternative specification by adding triple interaction terms to this production function.

${ }^{17}$ We replace quantity with the deflated revenue of total sales since production quantity data is unavailable at the firm level. In other words, the firm-level estimation uses the deflated revenue as a proxy of $q_{f t}$ for each firm, where the 4-digit Chinese Industrial Classification (CIC) industry-level output deflators are taken from Brandt, Van Biesebroeck and Zhang (2012). Note that we do have quantity data for only exported products and will use this information for each exported product when we estimate firm-product markups of exported product later. As for robustness checks, we will also employ a new dataset that contains physical quantity of output $q_{f t}$ for single-product firms only. Our results are robust to various measures of firm-product markups, as can been seen in Section 5.3 and 6.1.
} 
project product $h$ 's export quantity $q_{f h t}$ in year $t$ on a list of variables to obtain its predicted value. The variables in the list include inputs, input/output tariffs, the output price, processing trade dummies, interactions between processing trade dummies and input/output tariffs, region-industry-product dummies, and time fixed effects. ${ }^{18}$

Next we compute a firm-product-specific term $\widehat{\varphi}_{f h t}: \widehat{\varphi}_{f h t}=E\left(q_{f h t}\right)-f\left(x_{f t}, \widehat{\beta}\right)$. Using equation (15), $\widehat{\varphi}_{f h t}$ satisfies:

$$
\widehat{\varphi}_{f h t}=\varphi_{f t}+A_{f h t}\left(\rho_{f h t} ; x_{f t} ; \widehat{\beta}\right)=\varphi_{f t}+\widehat{a}_{f t} \rho_{f h t}+\widehat{b}_{f t} \rho_{f h t}^{2}
$$

where the second equal sign follows from applying our translog production function to $A_{f h t}(\cdot)$. The coefficient terms $\widehat{a}_{f t}$ and $\widehat{b}_{f t}$ are both functions of the estimated parameter vector $\widehat{\beta} .^{19}$

Given $\widehat{\varphi}_{f h t}$, $\widehat{a}_{f t}$ and $\widehat{b}_{f t}$, we can then calculate the firm's productivity and input allocations for each year. Specifically, we solve for the $J+1$ unknowns $\left(\varphi_{f t}, \rho_{f 1 t}, \ldots, \rho_{f J t}\right)$ in a system of $J+1$ equations. ${ }^{20}$ Note that we need to modify the proportional assumption made in De Loecker et al. (2016), which says that the sum of input shares across products equals to one. This modification is due to limitations of the Chinese trade data. Most firms in our sample are not pure exporters and, therefore, they also have domestic sales that are not observable at the firm-product level. As a result, we cannot borrow the assumption from De Loecker et al. (2016). ${ }^{21}$ Instead, following Kee and Tang (2016), we

\footnotetext{
${ }^{18}$ We also measure firm-product markups by projecting deflated export revenue instead of export quantity. We find that doing this would not qualitatively affect our main results. The empirical results based on other projection methods are available upon request.

${ }^{19}$ The coefficient terms $\widehat{a}_{f t}$ and $\widehat{b}_{f t}$ respectively satisfy:

$$
\begin{aligned}
\widehat{a}_{f t} & =\widehat{\beta}_{l}+\widehat{\beta}_{m}+\widehat{\beta}_{k}+2\left(\widehat{\beta}_{l l} l_{f t}+\widehat{\beta}_{m m} m_{f t}+\widehat{\beta}_{k k} k_{f t}\right) \\
& +\widehat{\beta}_{l m}\left(l_{f t}+m_{f t}\right)+\widehat{\beta}_{l k}\left(l_{f t}+k_{f t}\right)+\widehat{\beta}_{m k}\left(m_{f t}+k_{f t}\right) ; \\
\widehat{b}_{f t} & =\widehat{\beta}_{l l}+\widehat{\beta}_{m m}+\widehat{\beta}_{k k}+\widehat{\beta}_{l m}+\widehat{\beta}_{l k}+\widehat{\beta}_{m k} .
\end{aligned}
$$

${ }^{20}$ This system of $J+1$ equations consists of the following equations:

$$
\begin{gathered}
\widehat{\varphi}_{f 1 t}=\varphi_{f t}+a_{f t} \rho_{f 1 t}+b_{f t} \rho_{f 1 t}^{2} \\
\cdots \cdots \\
\widehat{\varphi}_{f J t}=\varphi_{f t}+a_{f t} \rho_{f J t}+b_{f t} \rho_{f J t}^{2}
\end{gathered}
$$

plus the equation that the sum of $\rho_{f h t}$ over the product line for any firm $f$ at time $t$ equals the share of total export in the total sales of that firm. This last equation differs from the equation used in De Loecker et al. (2016): the sum of $\rho_{f h t}$ over all products for any firm $f$ at time $t$ equals to one.

${ }^{21}$ Section 5.3 and 6.1 show that this assumption plays little role in this paper, since our results stay virtually unchanged when we maintain the original assumption and repeat our analysis in a subsample of pure Chinese exporters.
} 
assume that the share of inputs allocated to exports production is proportional to the share of exporting value in total sales. This implies that, for any firm $f$ at time $t$, the sum of $\rho_{f h t}$ across products is equal to the ratio of total exports to total sales.

A numerical procedure is conducted in solving the aforementioned system of $J+1$ equations for each firm and each year. ${ }^{22}$ We now have all the ingredients to compute markups and the implied marginal costs for multi-product firms according to equation (13):

$$
\widehat{\mu}_{f h t}=\ln \left(\widehat{\theta}_{f h t}^{M} \frac{P_{f h t} Q_{f h t}}{\exp \left(\widehat{\rho}_{f h t}\right) P_{f t}^{M} V_{f t}^{M}}\right)
$$

where the product-specific output elasticity for materials $\widehat{\theta}_{f h t}^{M}$ is a function of the production function coefficient, $P_{f h t} Q_{f h t}$ is product $h$ 's export value directly obtained from the customs data, and $\exp \left(\widehat{\rho}_{f h t}\right) P_{f t}^{M} V_{f t}^{M}$ denotes the materials allocated to produce product $h .^{23}$

Finally, marginal costs for product $h$ at time $t$ are recovered by subtracting the markup from the log price according to the following equation:

$$
\widehat{m c}_{f h t}=\ln \left(P_{f h t}\right)-\widehat{\mu}_{f h t}
$$

Table A.1 in the Appendix summarizes our markup estimates for ordinary trade observations (columns 1 to 5) and processing trade observations (columns 6 to 10). For each trade regime, we also employ other approaches to measure firm-product markups. These approaches include the use of an additional quantity-based dataset, an alternative production function specification, a small sample that includes only pure exporters, and a theoretical markup measure that only requires observable market shares and substitution elasticities. The benchmark estimates are reported in columns 1 and 6 , and the additional four estimates are reported in columns 2 and 7, columns 3 and 8, columns 4 and 9, and columns 5 and 10, sequentially. In all sectors, the average markup is higher than 1. The highest firm-product markup for ordinary trade firms occurs in the industry of Communication Equipment, Computers and Other Electronic Equipment (2-digit CIC

\footnotetext{
${ }^{22}$ Similar to De Loecker et al. (2016), we find that conditional on converging to an interior solution (i.e., all the product's input shares fall in the range between 0 and the ratio of total exports to total sales of that firm, non-inclusive), the solution for the equation system is unique regardless of what initial values are assigned to all unknowns. Out of the total sample of multi-product firm-year pairs, we drop no more than $0.5 \%$ of all observations in the total sample to eliminate the possibility of having a corner solution.
}

${ }^{23}$ The expression of the materials output elasticity for product $h$ at time $t$ is:

$$
\widehat{\theta}_{f h t}^{M}=\widehat{\beta}_{m}+2 \widehat{\beta}_{m m}\left(\widehat{\rho}_{f h t}+m_{f t}\right)+\widehat{\beta}_{l m}\left(\widehat{\rho}_{f h t}+l_{f t}\right)+\widehat{\beta}_{m k}\left(\widehat{\rho}_{f h t}+k_{f t}\right)
$$


industry code 40).

\subsection{Measure of tariff}

To construct measures for output tariffs, we first draw the tariff lines from the WTO and from the trade analysis and information system (TRAINS). Then, we map two coding systems: the harmonized system (HS) 8-digit codes used to categorize tariffs, and the 3-digit-input-output table from China that is used to classify products. After the mapping, our 3-digit output tariffs are just the simple average of all tariffs that fall into the corresponding category of the 3 -digit IO industry code. ${ }^{24}$

To compute measures for input tariffs, we adopt the approach suggested by Amiti and Konings (2007), and use an input-cost weighted average of output tariffs:

$$
\tau_{i t}^{\text {input }}=\sum_{k} a_{k i} \tau_{k t}^{\text {output }}
$$

In this equation, $\tau_{k t}^{\text {output }}$ is the output tariff imposed on industry $k$ at time $t ; a_{k i}$ is the weight assigned to industry $k$, or equivalently, it is the percentage of industry $i$ 's total costs that were expended on products supplied by industry $k$ as intermediate inputs for industry $i$. For instance, if industry $i$ incurs $80 \%$ of its total costs in steel and $20 \%$ of its total costs in rubber, then when we calculate the input tariff in industry $i$, we would assign an $80 \%$ weight on the steel industry's output tariff and a $20 \%$ weight on the rubber industry's output tariff.

Since our production data utilizes the CIC 4-digit codes, we still need to map IO 3digit tariffs into the CIC coding system. This procedure yields a set of input and output tariffs at the CIC 4-digit level, which constitutes the foundation for our main results. Nevertheless, we report the results using firm-level and HS6 product-level input/output tariffs as well (see Section 6.2), and our main results remain unchanged. At the industry level, Figure 3 presents our calculations for input and output tariffs in China during 20002006. These downward-sloping lines reveal that the Chinese tariff rates have dropped drastically since China became a member of the WTO in 2001.

\section{$5 \quad$ Specifications and main results}

This section describes our econometric models and presents the associated regression results. The baseline specification is estimated based on the sample of ordinary trading

\footnotetext{
${ }^{24}$ Here we use the 2002 version of IO table. Replacing it with the 2007 version of the IO table would not affect our results.
} 
Figure 3: Annual Output and Input Tariffs in China (2000-2006)

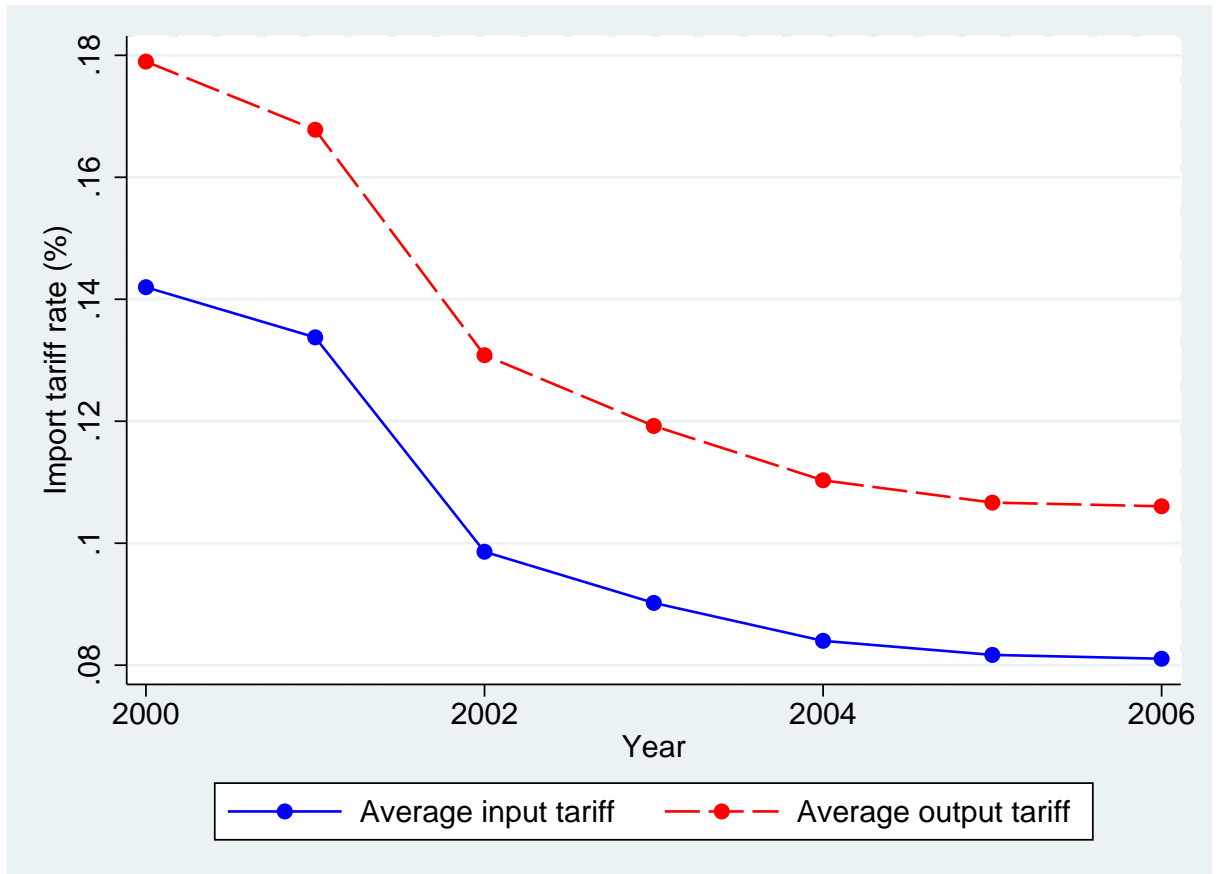

firms. We use processing exporters (never subject to import tariffs) as a placebo sample to verify the causal effect of tariff reductions on markup raises. If we decompose markup into output elasticity and input share, and regress each of them on our explanatory variables, the results are supportive to the baseline outcomes.

Then, we test the marginal-cost and the import-dependence effects, which are argued by our theory as underlying mechanisms driving the causal relation of interests. Next, we discuss movements in export prices and the role played by quality adjustments. After that, we experiment with different estimates of firm-product markups (based on the new quantity-based data, an alternative production function, a subsample of pure exporters, and a procedure implied by the model) to validate the baseline results. Finally, we alter our empirical specifications by incorporating difference estimators and instrumental variables.

\subsection{Trade liberalization effects on markups}

We quantitatively examine in this part how firms' markups respond to tariff reductions during trade liberalization in China. Table 1 reports the summary statistics of key variables in our sample, such as markups, tariffs, and firm- and industry-level characteristics. Recall that the sample is divided into two regimes: ordinary trade and processing trade.

Baseline regression.- Our model suggests that, besides the typical pro-competitive 
Table 1: Summary Statistics of Key Variables

\begin{tabular}{|c|c|c|c|c|c|c|}
\hline \multirow[b]{2}{*}{ Variable } & \multicolumn{3}{|c|}{ Ordinary Trade } & \multicolumn{3}{|c|}{ Processing Trade } \\
\hline & Mean & Median & S.D. & Mean & Median & S.D. \\
\hline $\log ($ markup $)$ & 0.04 & 0.11 & 2.69 & -0.08 & 0.13 & 2.27 \\
\hline Input tariff & 0.1 & 0.09 & 0.03 & 0.11 & 0.1 & 0.04 \\
\hline Output tariff & 0.13 & 0.13 & 0.06 & 0.15 & 0.15 & 0.06 \\
\hline $\log (\mathrm{TFP})$ & 0.13 & -0.04 & 0.61 & 0.09 & -0.05 & 0.59 \\
\hline $\log ($ Labor $)$ & 5.73 & 5.65 & 1.2 & 5.95 & 5.87 & 1.15 \\
\hline $\log$ (Capital/Labor) & 3.79 & 3.79 & 1.21 & 3.67 & 3.63 & 1.22 \\
\hline $\log$ (Wage) & 2.57 & 2.53 & 0.6 & 2.53 & 2.51 & 0.61 \\
\hline Industry wage & 13.49 & 13.01 & 5 & 12.73 & 11.9 & 4.62 \\
\hline Industry capital intensity & 68.28 & 53.24 & 55.89 & 58.47 & 44.8 & 52.9 \\
\hline Industry skill intensity & 0.02 & 0.02 & 0.02 & 0.02 & 0.01 & 0.01 \\
\hline Herfindahl index & 0.02 & 0.01 & 0.03 & 0.01 & 0.01 & 0.03 \\
\hline
\end{tabular}

effects caused by changes in output tariffs, trade liberalization may affect firm markups via the marginal-cost channel brought up by changes in input tariffs. To test the overall effect of trade liberalization on markups, we adopt the following regression equation as our baseline specification:

$$
\mu_{f h t}=\kappa_{1} \text { input_tariff }_{i t}+\kappa_{2} \text { output_tariff }{ }_{i t}+\boldsymbol{\kappa}_{3} \boldsymbol{E}_{f t}+\boldsymbol{\kappa}_{4} \boldsymbol{S}_{i t}+\delta_{t}+\delta_{s}+\delta_{f h}+\epsilon_{f h t}
$$

where $\mu_{f h t}$ denotes the estimated firm-product markups for HS6 product $h$ produced by firm $f$ in year $t$, and the subscript $i$ denotes a 4 -digit CIC industry. The vector of firm-level controls, $\boldsymbol{E}_{f t}$, accounts for firm characteristics, such as productivity, size of employment, capital-labor ratio, and average wage, that could potentially influence markups. The vector of industry-level controls, $\boldsymbol{S}_{i t}$, includes industrial average wage (WAGE), capital intensity $(K L)$, skill intensity measured by the ratio of college workers to total employees $(S K I L L)$, and the Herfindahl index $(H H I)$. These industry characteristics are computed at the 4-digit CIC level each year to capture the endowment and competition effects in any industry. We also control for the time fixed effect $\left(\delta_{t}\right)$, the 2-digit CIC sector/industry fixed effect $\left(\delta_{s}\right)$, and the firm-product fixed effect $\left(\delta_{f h}\right)$, to account for all factors that are time-varying, sector, and firm-product related. Because industry-level tariffs are the variables of interest in equation (19), we cluster error terms at the industry-year pair to address the issue of potential correlations between errors within each industry over time. Our baseline model predicts a negative coefficient on 
input tariffs for ordinary trade firms, and an insignificant effect of trade liberalization on markups for the placebo sample of processing trade firms who are, by law, not subject to import duties. The placebo results will be reported in comparison with the results for ordinary trade.

Table 2: Impact of Tariffs on Markups

\begin{tabular}{|c|c|c|c|c|c|c|c|c|}
\hline \multicolumn{5}{|c|}{$\begin{array}{l}\text { le: Firm-product markup } \\
\qquad \text { Sample of Ordinary Trade }\end{array}$} & \multicolumn{4}{|c|}{ Sample of Processing Trade } \\
\hline & $(1)$ & $(2)$ & (3) & (4) & $(5)$ & (6) & (7) & (8) \\
\hline Input tariff & $\begin{array}{c}-2.793^{* *} \\
(1.214)\end{array}$ & $\begin{array}{c}-2.384^{* *} \\
(1.170)\end{array}$ & $\begin{array}{c}-4.454^{* * *} \\
(1.372)\end{array}$ & $\begin{array}{c}-3.443^{* * *} \\
(1.299)\end{array}$ & $\begin{array}{c}0.168 \\
(2.023)\end{array}$ & $\begin{array}{c}0.548 \\
(1.828)\end{array}$ & $\begin{array}{l}-0.709 \\
(1.734)\end{array}$ & $\begin{array}{c}0.336 \\
(1.577)\end{array}$ \\
\hline Output tariff & $\begin{array}{c}0.915 \\
(0.876)\end{array}$ & $\begin{array}{c}0.771 \\
(0.850)\end{array}$ & $\begin{array}{l}1.525^{*} \\
(0.907)\end{array}$ & $\begin{array}{l}1.279 \\
(0.840)\end{array}$ & $\begin{array}{l}-1.687 \\
(2.228)\end{array}$ & $\begin{array}{l}-1.455 \\
(1.989)\end{array}$ & $\begin{array}{l}-0.728 \\
(1.579)\end{array}$ & $\begin{array}{l}-0.612 \\
(1.417)\end{array}$ \\
\hline $\log (\mathrm{TFP})$ & & $\begin{array}{c}0.920^{* * *} \\
(0.051)\end{array}$ & & $\begin{array}{c}0.974^{* * *} \\
(0.041)\end{array}$ & & $\begin{array}{c}0.948^{* * *} \\
(0.055)\end{array}$ & & $\begin{array}{c}1.020^{* * *} \\
(0.042)\end{array}$ \\
\hline $\log ($ Labor $)$ & & $\begin{array}{l}-0.050 \\
(0.032)\end{array}$ & & $\begin{array}{l}-0.046 \\
(0.029)\end{array}$ & & $\begin{array}{c}0.001 \\
(0.038)\end{array}$ & & $\begin{array}{l}-0.035 \\
(0.036)\end{array}$ \\
\hline $\log$ (Capital/Labor) & & $\begin{array}{c}0.023 \\
(0.022)\end{array}$ & & $\begin{array}{c}0.010 \\
(0.024)\end{array}$ & & $\begin{array}{c}0.072^{* * *} \\
(0.027)\end{array}$ & & $\begin{array}{c}0.049^{* *} \\
(0.023)\end{array}$ \\
\hline $\log$ (Wage) & & $\begin{array}{c}0.021 \\
(0.021)\end{array}$ & & $\begin{array}{c}0.023 \\
(0.022)\end{array}$ & & $\begin{array}{c}0.020 \\
(0.020)\end{array}$ & & $\begin{array}{c}0.008 \\
(0.020)\end{array}$ \\
\hline WAGE & & $\begin{array}{c}0.002 \\
(0.003)\end{array}$ & & $\begin{array}{c}0.002 \\
(0.004)\end{array}$ & & $\begin{array}{l}-0.002 \\
(0.004)\end{array}$ & & $\begin{array}{l}-0.001 \\
(0.004)\end{array}$ \\
\hline KL & & $\begin{array}{c}0.000 \\
(0.000)\end{array}$ & & $\begin{array}{c}0.000 \\
(0.000)\end{array}$ & & $\begin{array}{l}-0.000 \\
(0.000)\end{array}$ & & $\begin{array}{l}-0.000 \\
(0.001)\end{array}$ \\
\hline SKILL & & $\begin{array}{c}1.482 \\
(2.457)\end{array}$ & & $\begin{array}{c}0.008 \\
(2.426)\end{array}$ & & $\begin{array}{c}5.746 \\
(5.556)\end{array}$ & & $\begin{array}{c}5.022 \\
(5.760)\end{array}$ \\
\hline HHI & & $\begin{array}{c}0.656 \\
(0.409)\end{array}$ & & $\begin{array}{c}0.708 \\
(0.476)\end{array}$ & & $\begin{array}{c}0.289 \\
(0.548)\end{array}$ & & $\begin{array}{c}0.222 \\
(0.556)\end{array}$ \\
\hline Year Fixed Effect & YES & YES & YES & YES & YES & YES & YES & YES \\
\hline Industry Fixed Effect & YES & YES & YES & YES & YES & YES & YES & YES \\
\hline Firm-Product Fixed Effect & YES & YES & YES & YES & YES & YES & YES & YES \\
\hline Observations & 575824 & 575824 & 575824 & 575824 & 168813 & 168813 & 168813 & 168813 \\
\hline R-squared & 0.876 & 0.877 & 0.858 & 0.859 & 0.859 & 0.861 & 0.846 & 0.849 \\
\hline
\end{tabular}

Notes: ${ }^{* * *} \mathrm{p}<0.01,{ }^{* *} \mathrm{p}<0.05,{ }^{*} \mathrm{p}<0.1$. Robust standard errors corrected by clustering variables at the industryyear level are in parentheses. Specifications 1-4 refer to ordinary trade, and specifications 5-8 refer to processing trade. In specifications 3-4 and 7-8 we run regressions weighted by the number of observations in each 2-digit CIC industry.

Ordinary trade.-First of all, we run several regressions specified by equation (19) with ordinary trade observations. The results are reported in columns 1 to 4 of Table 2. As can be seen, the estimated coefficients of input tariffs are significantly negative. In terms of magnitude, a $1 \%$ reduction in input tariff leads to a markup increase by $2-3 \%$ for unweighted regressions (columns 1 and 2), and a markup increase by $3-4 \%$ for weighted regressions (columns 3 and 4). In each pair of columns (columns 1 and 2 and columns 3 and 4), the first column and the second column respectively report the results 
"without" and "with" controlling for firm/industry-level characteristics. The magnitude of input-tariff effects on markups is fairly stable across all four columns.

We run weighted regressions in columns 3 and 4 because markups are estimated with various degrees of accuracy and we would like to reflect our priorities on high-precision estimates. Since production function estimations (which generate markup estimates) are conducted at the 2-digit CIC sector level, we are more confident about a firm-product markup estimate when there are more observations in the firm-product's parent sector. Thus, following De Loecker et al. (2016), we weigh conventional regressions by the number of observations used to estimate each 2-digit CIC sector production function. Our coefficients of interest in columns 3 and 4 have the same sign as those in columns 1 and 2 , but the magnitude of coefficients in weighted regressions is larger than the magnitude of those in unweighted regressions. This suggests that we have successfully pulled the regressions towards matching markups in the high-precision region.

Turning to the output-tariff effects on markups, the corresponding coefficients are positive but only occasionally significant. This is consistent with the pro-competitive effects that have been intensively studied in the previous literature: lower output tariffs during trade liberalization intensify competition in the final goods market and thus reduce domestic firms' pricing power and markups. Note that the coefficients on TFP are significantly positive. This indicates that more productive firms would charge higher markups, providing supportive evidence to Proposition 1.

Processing trade.- Secondly, we repeat the above regressions with processing trade observations. As firms that conduct processing trade are not subject to tariffs, we expect the impact of tariffs to be absent among those firms. Results in columns 5 to 8 of Table 2 confirm our belief: in all specifications employed, none of them suggests that import tariffs (both input and output tariffs) significantly affect the processing trade firms' markups.

Decomposition of markup.-Lastly, when estimating firm-product (log) markups, we recover estimates for firm-product specific output elasticity $\theta$ and firm-product specific share of input expenditure $\alpha$. According to equation (13), an estimated (log) markup is the (log) ratio of output elasticity to input share. Therefore, we can decompose the markup into two components, $\theta$ and $\alpha$, and separately regress these two components on input tariffs.

But regressing $\theta$ on tariffs is inconsistent with our model, as it assumes a CobbDouglas production function, in which $\theta$ is a constant unaffected by tariff reductions and only $\alpha$ falls with input-tariff reductions. To solve this inconsistency issue, we deviate from our theory by assuming a translog production function, in which $\theta$ is no longer a constant but $\alpha$ still falls with input-tariff reductions. Since a translog output depends on the squares of capital, labor, and material, as well as the interaction terms between any two of all squared terms, input-tariff reductions induce production to expand more 
via more labor employed, more materials depleted, or more capital invested, and hence generate a higher output elasticity.

Given translog production functions are utilized in markup estimations (see Section 4.3), we can empirically test the effect of input-tariff reductions on either $\theta$ or $\alpha$. The results are shown in Table A.2 in the Appendix. ${ }^{25}$ As expected, for the ordinary trade sample (columns 1 and 2 of Table A.2), when the dependent variable is output elasticity, the coefficients on input tariffs are significantly negative, bearing the same sign when we regress markups on tariffs, while for the processing trade sample (columns 3 and 4 of Table A.2), the significance disappears. In contrast, when the dependent variable is $\alpha$, the coefficients on input tariffs become significantly positive, suggesting a lower share of input expenditure after tariff reductions. Again, this pattern applies only to the ordinary trade sample but not to the processing trade sample.

\subsection{The underlying mechanisms}

Import dependence channel.-Our model studies markup adjustments by an incumbent trading firm that imports intermediate inputs. The predictions are that a reduction in tariffs would lead to an increase in markups, and this effect would be more profound for firms with higher import intensity. The theoretical mechanism underlying the latter prediction is described as follows.

During trade liberalization, import-tariff reductions decrease the price index $P_{M}$ of imported inputs and hence lower the cost-reduction factor $B$. If we let $\tau_{h}=\tau$ for all imported inputs, then the change in the cost-reduction factor after import-tariff reductions should satisfy:

$$
\Delta \ln B \equiv \frac{\left(P_{M}\right)^{1-\varsigma}}{\left(P_{Z}\right)^{1-\varsigma}+\left(P_{M}\right)^{1-\varsigma}} d \ln \tau
$$

where $\frac{\left(P_{M}\right)^{1-\varsigma}}{\left(P_{Z}\right)^{1-\varsigma}+\left(P_{M}\right)^{1-\varsigma}}$ is the share of total input expenditures spent on imported intermediates. Consider any firm with a higher import share, import-tariff reductions would result in a larger decline in $\ln B$, and hence a larger decline in $\ln c$ with $c$ denoting the marginal cost (see equation (6)). ${ }^{26} \mathrm{~A}$ smaller marginal cost in turn leads to higher markups.

Therefore, we expect that importers would extract more benefits from tariff reductions than non-importers, and given all other conditions being equal, an importing firm with

\footnotetext{
${ }^{25}$ Nevertheless, we repeat these regressions with Cobb-Douglas production functions. The results stay unchanged and are available upon request.

${ }^{26}$ The effect of import-tariff reductions on marginal costs satisfies: $\Delta \ln c \equiv \eta \Delta \ln B \equiv$ $\eta \frac{\left(P_{M}\right)^{1-\varsigma}}{\left(P_{Z}\right)^{1-\varsigma}+\left(P_{M}\right)^{1-\varsigma}} d \ln \tau$.
} 
Table 3: The Effect of Tariffs on Markups through the Import-Dependence Channel

\begin{tabular}{|c|c|c|c|c|c|c|c|c|}
\hline \multicolumn{3}{|c|}{$\begin{array}{l}\text { Dependent variable: Firm-product markups } \\
\qquad \underline{\text { unweighted ordinary }}\end{array}$} & \multicolumn{2}{|c|}{ weighted ordinary } & \multicolumn{2}{|c|}{ unweighted processing } & \multicolumn{2}{|c|}{ weighted processing } \\
\hline & (1) & $(2)$ & $(3)$ & (4) & $(5)$ & (6) & (7) & $(8)$ \\
\hline Input tariff & $\begin{array}{l}-1.315 \\
(1.248)\end{array}$ & $\begin{array}{l}-2.004 \\
(1.220)\end{array}$ & $\begin{array}{l}-1.917 \\
(1.408)\end{array}$ & $\begin{array}{c}-3.075^{* *} \\
(1.331)\end{array}$ & $\begin{array}{l}-0.920 \\
(2.511)\end{array}$ & $\begin{array}{c}0.441 \\
(2.000)\end{array}$ & $\begin{array}{c}0.235 \\
(2.152)\end{array}$ & $\begin{array}{c}0.279 \\
(1.682)\end{array}$ \\
\hline Output tariff & $\begin{array}{c}0.718 \\
(0.850)\end{array}$ & $\begin{array}{c}0.777 \\
(0.854)\end{array}$ & $\begin{array}{l}1.176 \\
(0.834)\end{array}$ & $\begin{array}{l}1.299 \\
(0.838)\end{array}$ & $\begin{array}{l}-1.448 \\
(1.990)\end{array}$ & $\begin{array}{l}-1.471 \\
(1.985)\end{array}$ & $\begin{array}{l}-0.611 \\
(1.416)\end{array}$ & $\begin{array}{l}-0.621 \\
(1.412)\end{array}$ \\
\hline Input tariff $\times$ Importing firm & $\begin{array}{c}-1.267^{* * *} \\
(0.450)\end{array}$ & & $\begin{array}{c}-1.763^{* * *} \\
(0.489)\end{array}$ & & $\begin{array}{c}1.447 \\
(1.648)\end{array}$ & & $\begin{array}{c}0.094 \\
(1.791)\end{array}$ & \\
\hline Importing firm & $\begin{array}{c}0.168^{* * *} \\
(0.049)\end{array}$ & & $\begin{array}{c}0.220^{* * *} \\
(0.051)\end{array}$ & & $\begin{array}{l}-0.181 \\
(0.177)\end{array}$ & & $\begin{array}{l}-0.034 \\
(0.179)\end{array}$ & \\
\hline Input tariff $\times$ Import share & & $\begin{array}{c}-3.105^{*} \\
(1.634)\end{array}$ & & $\begin{array}{c}-3.752^{* * * *} \\
(1.322)\end{array}$ & & $\begin{array}{c}0.308 \\
(1.134)\end{array}$ & & $\begin{array}{c}0.146 \\
(0.750)\end{array}$ \\
\hline Import share & & $\begin{array}{c}0.686^{* * *} \\
(0.211)\end{array}$ & & $\begin{array}{c}0.704^{* * *} \\
(0.176)\end{array}$ & & $\begin{array}{c}0.034 \\
(0.156)\end{array}$ & & $\begin{array}{c}0.033 \\
(0.123)\end{array}$ \\
\hline $\log (\mathrm{TFP})$ & $\begin{array}{c}0.919^{* * *} \\
(0.051)\end{array}$ & $\begin{array}{c}0.903^{* * *} \\
(0.051)\end{array}$ & $\begin{array}{c}0.972^{* * *} \\
(0.041)\end{array}$ & $\begin{array}{c}0.958^{* * *} \\
(0.042)\end{array}$ & $\begin{array}{c}0.948^{* * *} \\
(0.055)\end{array}$ & $\begin{array}{c}0.942^{* * *} \\
(0.056)\end{array}$ & $\begin{array}{c}1.020^{* * *} \\
(0.042)\end{array}$ & $\begin{array}{c}1.014^{* * *} \\
(0.044)\end{array}$ \\
\hline Other Firm-level Controls & YES & YES & YES & YES & YES & YES & YES & YES \\
\hline Industry-level Controls & YES & YES & YES & YES & YES & YES & YES & YES \\
\hline Year Fixed Effect & YES & YES & YES & YES & YES & YES & YES & YES \\
\hline Industry Fixed Effect & YES & YES & YES & YES & YES & YES & YES & YES \\
\hline Firm-Product Fixed Effect & YES & YES & YES & YES & YES & YES & YES & YES \\
\hline Observations & 575824 & 575824 & 575824 & 575824 & 168813 & 168813 & 168813 & 168813 \\
\hline R-squared & 0.877 & 0.877 & 0.859 & 0.859 & 0.861 & 0.861 & 0.849 & 0.849 \\
\hline
\end{tabular}

Notes: ${ }^{* * *} \mathrm{p}<0.01,{ }^{* *} \mathrm{p}<0.05,{ }^{*} \mathrm{p}<0.1$. Robust standard errors corrected by clustering variables at the industryyear level are in parentheses. Specifications 1-4 refer to ordinary trade, and specifications 5-8 refer to processing trade. In columns 1-2 and 5-6 we run unweighted regressions, and in columns 3-4 and 7-8 we run regression weighted by the number of observations in each 2-digit CIC industry. Other firm-level controls include firm size measured by employment, capital-labor ratio, and average wage; industry-level controls include industry average wage, capital intensity, share of college-trained employees, and the Herfindahl index at the 4-digit CIC industry level. The results stay unchanged when we exclude firm-level and industry-level controls.

higher import intensity would gain more than its peers with lower import intensity:

$$
\begin{aligned}
\mu_{f h t} & =\kappa_{1} \text { input_tariff }_{i t}+\kappa_{2} \text { output_tariff }_{i t}+\kappa_{5} \text { import_status }_{f t} \\
& +\kappa_{\text {im }} \text { input_tariff }_{i t} \text { import_status }_{f t}+\boldsymbol{\kappa}_{3} \boldsymbol{E}_{f t}+\boldsymbol{\kappa}_{4} \boldsymbol{S}_{i t}+\delta_{t}+\delta_{s}+\delta_{f h}+\epsilon_{f h t}
\end{aligned}
$$

where the firm-specific variable import_status could either be a dummy, importing firm, which equals one for an importer and zero otherwise, or a continuous variable, import share, which is the firm's import intensity measured by the ratio of the cost of imported inputs to the total cost of all intermediate inputs. In estimating equation (21), we expect the coefficient on import_status, $\kappa_{5}$, to be significantly positive, and the coefficient on the interaction term, $\kappa_{i m}$, to be significantly negative. This implies that a firm that imports more tends to be more affected by input-tariff reductions and is more 
likely to adjust markup to a higher level, ceteris paribus. Results reported in Table 3 conform to our expectations.

In Table 3, results for ordinary trade are shown in columns 1-4 to compare with results for processing trade in columns 5-8. Columns 1 and 2, and 5 and 6 use unweighted regressions, while columns 3 and 4, and 7 and 8 adopt weighted regressions. For an average importer under the ordinary trade regime, the impact of input tariffs on markups is $96 \%$ higher, with an unweighted regression in column 1, and $92 \%$ higher, with a weighted regression in column 3 , than its non-importing counterpart in corresponding columns 5 and 7 . To be more precise, when we use the share rather than a dummy to measure import intensity, a 10\% increase in an average importer's import intensity (compared with non-importing firms) raises the input-tariff impact by about $15 \%$ for an unweighted regression in column 2 and by $12 \%$ for a weighted regression in column 4 . Note that, in all specifications, the coefficients on the interaction term, $\kappa_{i m}$, are always significantly negative for ordinary trades, but will turn insignificant for processing trades. In sum, ordinary trade firms with higher import intensity adjust markups more during trade liberalization.

It is worth noting, however, that once we control for the interaction between input tariff and import intensity, the coefficient of input tariff becomes less significant (columns 1-4 of Table 3 in contrast to columns 1-4 of Table 2). This is because our sample includes both importers and non-importers. For importers, an input tariff reduction will significantly raise their markups. In contrast, for non-importers, a decrease in input tariff will not directly lower marginal costs, and hence the effect of input tariff on non-importers markup would be insignificant; however, this effect is still negative because some nonimporters may use domestic inputs supplied by importers. In columns 1-4 of Table 2, when import status and its interaction with input tariff are excluded, $\kappa_{1}$ captures the overall effect of input tariff on markup for a pool of importers and non-importers. So its estimates are significantly negative. Turning to Table 3, when import status and the interaction terms are added back, the direct effect of input tariff on importers markup is absorbed by $\kappa_{5}$ and $\kappa_{i m}$. As a result, $\kappa_{1}$ now represents only the indirect effect of input tariff on non-importers markup, and hence its estimates become less significant than the corresponding counterparts reported in Table 2.

Our empirical findings are also consistent with Amiti, Itskhoki and Konings (2014), in which the authors show a positive correlation between import intensity and market share, and moreover, they show that firms with larger market shares (therefore stronger market power and higher markups) adjust markups more drastically in response to trade liberalization. Therefore, our result that firms with higher import intensity greatly adjust markups upon tariff reductions complements their work. In placebo tests using the sample of processing trades, as can be seen from columns 5 to 8 of Table 3 , we observe no 
significant effects for either the input tariff or its interaction with a firm's import status.

Marginal cost channel.- In our model, marginal cost is a function of import tariff $\tau$, conditional on firm productivity (see equations (6) and (20)). ${ }^{27}$ Our model predicts that trade liberalization via input-tariff reductions would lower the price index of imported inputs $P_{M}$ at first, and then lead to a fall in marginal costs while holding productivity still. We therefore regress estimated marginal costs on input- and output-tariff reductions directly with productivity controlled. The following specification is run with the hope of seeing a significantly positive coefficient on input_tariff:

$$
m c_{f h t}=\kappa_{1} \text { input_tariff }_{i t}+\kappa_{2} \text { output_tariff }_{i t}+\boldsymbol{\kappa}_{3} \boldsymbol{E}_{f t}+\boldsymbol{\kappa}_{4} \boldsymbol{S}_{i t}+\delta_{t}+\delta_{s}+\delta_{f h}+\epsilon_{f h t} .
$$

In addition to running the above specification, to further verify the importance of the marginal-cost channel, we augment our baseline regression (19) by controlling for marginal cost:

$\mu_{f h t}=\kappa_{1}$ input_tariff $_{i t}+\kappa_{2}$ output_tariff ${ }_{i t}+\kappa_{m c} m c_{f h t}+\boldsymbol{\kappa}_{3} \boldsymbol{E}_{f t}+\boldsymbol{\kappa}_{4} \boldsymbol{S}_{i t}+\delta_{t}+\delta_{s}+\delta_{f h}+\epsilon_{f h t}$.

If the marginal-cost channel indeed plays a role, then once the marginal costs are included as an explanatory variable, we would witness attenuation of the impact of input tariffs on markups. Hence the coefficient on marginal cost is of our interest in this augmented specification. A significantly negative estimate of $\kappa_{m c}$ would favor a marginalcost argument. More importantly, we expect the magnitude of the coefficient on input tariff when regressing equation (23) should be statistically insignificant. The results presented in Table 4 conform to our projections.

In columns 1-4 of Table 4, we present results for the ordinary trade sample. Using the specification in equation (22), when we regress marginal costs on tariff without controlling for firm- and industry-level characteristics, the coefficient on input tariff is significantly positive at the $10 \%$ level. That is, a $1 \%$ input tariff reduction would lead to a fall in marginal costs by approximately $2 \%$. But when we repeat this regression with all controls included, the estimated coefficient on input tariff becomes insignificant. This is due to multicollinearity between the added firm characteristics, in particular $\log (\mathrm{TFP})$, and the input tariff. The effect of tariff on marginal cost reduction is in large part functioning

\footnotetext{
${ }^{27}$ There is no information about prices of a Chinese firm's products sold in its domestic market. For this reason, we employ export prices to proxy domestic prices in calculating marginal costs. One advantage of using export prices as proxies is that we can distinguish between two trading regimes, ordinary and processing. This distinction plays a key role in our analysis.
} 
Table 4: The Effect of Tariffs on Markups through the Marginal-Cost Channel

\begin{tabular}{|c|c|c|c|c|c|c|c|c|}
\hline & \multicolumn{4}{|c|}{ Sample of Ordinary Trade } & \multicolumn{4}{|c|}{ Sample of Processing Trade } \\
\hline & (1) & $(2)$ & (3) & $(4)$ & $(5)$ & (6) & (7) & $(8)$ \\
\hline & \multicolumn{2}{|c|}{ marginal cost } & \multicolumn{2}{|c|}{ markup } & \multicolumn{2}{|c|}{ marginal cost } & \multicolumn{2}{|c|}{ markup } \\
\hline Input tariff & $\begin{array}{l}2.133^{*} \\
(1.178)\end{array}$ & $\begin{array}{c}1.771 \\
(1.207)\end{array}$ & $\begin{array}{l}-0.689 \\
(0.538)\end{array}$ & $\begin{array}{l}-0.610 \\
(0.511)\end{array}$ & $\begin{array}{l}-0.212 \\
(1.980)\end{array}$ & $\begin{array}{l}-0.587 \\
(1.806)\end{array}$ & $\begin{array}{l}-0.038 \\
(0.443)\end{array}$ & $\begin{array}{l}-0.019 \\
(0.438)\end{array}$ \\
\hline Output tariff & $\begin{array}{l}-0.859 \\
(0.902)\end{array}$ & $\begin{array}{l}-0.723 \\
(0.881)\end{array}$ & $\begin{array}{c}0.067 \\
(0.243)\end{array}$ & $\begin{array}{c}0.047 \\
(0.240)\end{array}$ & $\begin{array}{c}1.780 \\
(2.150)\end{array}$ & $\begin{array}{c}1.559 \\
(1.929)\end{array}$ & $\begin{array}{c}0.052 \\
(0.279)\end{array}$ & $\begin{array}{c}0.061 \\
(0.270)\end{array}$ \\
\hline Marginal cost & & & $\begin{array}{c}-0.987^{* * *} \\
(0.004)\end{array}$ & $\begin{array}{c}-0.986^{* * *} \\
(0.004)\end{array}$ & & & $\begin{array}{c}-0.977^{* * *} \\
(0.002)\end{array}$ & $\begin{array}{c}-0.977^{* * *} \\
(0.002)\end{array}$ \\
\hline $\log (\mathrm{TFP})$ & & $\begin{array}{c}-0.891^{* * *} \\
(0.051)\end{array}$ & & $\begin{array}{c}0.041^{* * *} \\
(0.012)\end{array}$ & & $\begin{array}{c}-0.917^{* * *} \\
(0.055)\end{array}$ & & $\begin{array}{c}0.053^{* * *} \\
(0.016)\end{array}$ \\
\hline Other Firm-level Controls & $\mathrm{NO}$ & YES & $\mathrm{NO}$ & YES & $\mathrm{NO}$ & YES & $\mathrm{NO}$ & YES \\
\hline Industry-level Controls & $\mathrm{NO}$ & YES & $\mathrm{NO}$ & YES & $\mathrm{NO}$ & YES & $\mathrm{NO}$ & YES \\
\hline Year Fixed Effect & YES & YES & YES & YES & YES & YES & YES & YES \\
\hline Industry Fixed Effect & YES & YES & YES & YES & YES & YES & YES & YES \\
\hline Firm-Product Fixed Effect & YES & YES & YES & YES & YES & YES & YES & YES \\
\hline Observations & 575824 & 575824 & 575824 & 575824 & 168813 & 168813 & 168813 & 168813 \\
\hline R-squared & 0.879 & 0.880 & 0.985 & 0.985 & 0.893 & 0.895 & 0.990 & 0.990 \\
\hline \multicolumn{9}{|c|}{$\begin{array}{l}\text { Notes: }{ }^{* * *} \mathrm{p}<0.01,{ }^{* *} \mathrm{p}<0.05, * \mathrm{p}<0.1 \text {. Robust standard errors corrected by clustering variables at the industry-year } \\
\text { level are in parentheses. Specifications 1-4 refer to ordinary trade, and specifications } 5-8 \text { refer to processing trade. In } \\
\text { columns } 1-2 \text { and } 5-6 \text {, the dependent variable is the firm-product-level marginal cost; in columns } 3-4 \text { and } 7-8 \text {, the dependent } \\
\text { variable is the firm-product-level markup. Other firm-level controls include firm size measured by employment, capital-labor } \\
\text { ratio, and average wage; industry-level controls include industry average wage, capital intensity, share of college-trained } \\
\text { employees, and the Herfindahl index at the } 4 \text {-digit CIC industry level. }\end{array}$} \\
\hline
\end{tabular}

through the channel of an increased TFP. ${ }^{28}$ Moreover, compared to the effect of tariff reduction on ordinary firms (see columns 1 and 2), input tariff reduction has insignificant and opposite impacts on processing firms' marginal costs (see columns 5 and 6).

In columns 2 and 6 of Table 4 , the coefficients on $\log (\mathrm{TFP})$ are significantly negative, suggesting a negative relation between firm productivity and marginal costs: a more productive firm has lower marginal costs regardless of the firm's trade regime. When we put marginal costs on the right-hand side of the baseline equation (23), the coefficients on marginal costs are significantly negative, but, as expected, the effect of input tariff becomes insignificant. This again provides a piece of evidence that supports our modeling strategy: a large part of the input-tariff effect operates through the marginal-cost channel. Incidentally, this empirical result also coincides with Proposition 1, which links higher efficiency (i.e., lower marginal costs) to higher markups. The marginal-cost channel works for both ordinary and processing trades, as we observe significantly negative coefficients on marginal costs when we appoint markups as the dependent variable in columns 7 and

\footnotetext{
${ }^{28}$ If we look at supplementary Table A.4, where we use an alternative measure for markup (calculated based on physical output data) to re-run the regressions in columns 1 and 2 of Table 4, the multicollinearity issue is mitigated, and the estimated coefficients of input tariff are $5 \%$ significant regardless of whether firm-level characteristics are present or not.
} 
8. In sum, for both types of firms, markup adjustments are mainly driven by changes in marginal costs, but the input-tariff effect is always absent for the processing trade sample (see columns 5 to 8 ).

Export prices and quality adjustments.-Our model has the advantage of analyzing movements of output prices, since equation (10) together with (12) yield the following expression for the optimal price:

$$
\Delta \ln p(\omega)=\frac{1}{1+(\sigma-1) \Gamma(1-s(\omega))} \Delta \ln c(\omega)
$$

Equation (24) basically says that a reduction in import tariff $\tau_{h}$ would lead to a fall in marginal cost $c$, and hence a decrease in export price. This implies a clear-cut effect of trade liberalization on output prices when there is no quality upgrading.

As argued by De Loecker et al. (2016), when firms can freely choose quality degrees, a drop in input tariffs would encourage firms to upgrade products' quality. Higher quality raises marginal costs, and increases output prices. ${ }^{29}$ Table 5 illustrates how output prices respond to tariff changes for ordinary (columns 1 to 4 ) and processing traders (columns 5 to 8): input-tariff reductions raise export prices for firms under the ordinary trade regime. This conclusion provides proof of quality upgrading during the sample period.

\subsection{Alternative estimates of firm-product markups}

This subsection estimates measures of firm-product markups using alternative methodologies, and checks the sensitivity of our benchmark results to these different measures. In particular, we will use an additional dataset (i.e. the quantity-based data), a different production function specification, and a smaller sample that includes only pure exporters. We will also depart from the De Loecker et al. (2016)'s methodology and rely on our own model to yield the measure of firm-product markup.

The benchmark results (see Tables 2-4) are obtained by estimating production function coefficients from the NBSC's firm-level production survey data. This dataset is revenue-based so it has to be deflated by the industry price index. However, it is possible that firms are subject to firm-specific prices. Hence using industry price index instead of firm-specific prices would create an omitted-variable bias (see a detailed illustration in De Loecker and Goldberg (2014)). To solve this omitted variables problem, we use a new database, that is, the physical-quantity firm-product production data for the period 2000-2006, which contains information on output quantity for each product (defined at

\footnotetext{
${ }^{29} \mathrm{Fan}, \mathrm{Li}$ and Yeaple (2015) also show that a reduction in input tariff induces firms to increase the quality and price of their exports, this is especially so for industries with a large scope of quality differentiation.
} 
Table 5: The Effects of Tariffs on Export Prices

\begin{tabular}{|c|c|c|c|c|c|c|c|c|}
\hline & \multicolumn{4}{|c|}{ Sample of Ordinary Trade } & \multicolumn{4}{|c|}{ Sample of Processing Trade } \\
\hline & \multicolumn{2}{|c|}{ unweighted ordinary } & \multicolumn{2}{|c|}{ weighted ordinary } & \multicolumn{2}{|c|}{ unweighted processing } & \multicolumn{2}{|c|}{ weighted processing } \\
\hline & (1) & $(2)$ & $(3)$ & (4) & (5) & (6) & (7) & (8) \\
\hline \multirow[t]{2}{*}{ Input tariff } & -0.660 & -0.585 & $-1.611^{* *}$ & $-1.443^{* *}$ & -0.043 & -0.033 & -0.663 & -0.657 \\
\hline & $(0.539)$ & $(0.515)$ & $(0.648)$ & $(0.599)$ & $(0.442)$ & $(0.439)$ & $(0.459)$ & $(0.456)$ \\
\hline \multirow[t]{2}{*}{ Output tariff } & 0.056 & 0.038 & 0.362 & 0.313 & 0.093 & 0.098 & $0.454^{*}$ & $0.501^{*}$ \\
\hline & $(0.245)$ & $(0.243)$ & $(0.307)$ & $(0.294)$ & $(0.263)$ & $(0.257)$ & $(0.262)$ & $(0.263)$ \\
\hline \multirow{2}{*}{$\log (\mathrm{TFP})$} & & $0.027^{* *}$ & & $0.042^{* * *}$ & & $0.032^{*}$ & & $0.048^{* *}$ \\
\hline & & $(0.012)$ & & $(0.014)$ & & $(0.016)$ & & $(0.024)$ \\
\hline Other Firm-level Controls & NO & YES & NO & YES & NO & YES & NO & YES \\
\hline Industry-level Controls & NO & YES & NO & YES & NO & YES & NO & YES \\
\hline Year Fixed Effect & YES & YES & YES & YES & YES & YES & YES & YES \\
\hline Industry Fixed Effect & YES & YES & YES & YES & YES & YES & YES & YES \\
\hline Firm-Product Fixed Effect & YES & YES & YES & YES & YES & YES & YES & YES \\
\hline Observations & 575824 & 575824 & 575824 & 575824 & 168813 & 168813 & 168813 & 168813 \\
\hline R-squared & 0.974 & 0.974 & 0.970 & 0.970 & 0.986 & 0.986 & 0.982 & 0.982 \\
\hline
\end{tabular}

Notes: The dependent variable is the output's unit price, defined as the deflated sales divided by quantities sold. $* * * \mathrm{p}$ $<0.01,{ }^{* *} \mathrm{p}<0.05,{ }^{*} \mathrm{p}<0.1$. Robust standard errors corrected by clustering variables at the industry-year level are in parentheses. Specifications 1-4 refer to ordinary trade, and specifications 5-8 refer to processing trade. Other firm-level controls include firm size measured by employment, capital-labor ratio, and average wage; industry-level controls include industry average wage, capital intensity, share of college-trained employees, and the Herfindahl index at the 4-digit CIC industry level.

the 5-digit product level) produced by each firm.

Fortunately, since this new database is also taken from the NBSC, it shares the same firm identification with the previous production survey data, enabling us to easily merge this new physical-quantity dataset with the existing survey data. When we use output quantities instead of deflated revenues to estimate production functions, we focus on single-product firms since all variables used in the estimation, except for output quantities, are only available at the firm-level. ${ }^{30}$ Moreover, we control for input prices (proxied by output prices), ${ }^{31}$ market shares, and export status as suggested by De Loecker et al. (2016), where they use a merged dataset (firm-level survey data plus quantity data) to measure production functions.

An alternative measure of firm-product markups can be generated by using physical

\footnotetext{
${ }^{30}$ Products from the physical-quantity firm-product production database are defined more broadly than those from the customs database. In other words, one product code in the physical-quantity database could correspond to several HS-6 digit codes. As a result, a single-product firm in the physical-quantity database turns into a multi-product firm after we merge the physical-quantity data with the customs data.

${ }^{31}$ Input price reflects input quality. As explained in De Loecker et al. (2016), the quality-adjustment mechanism would be alleviated if input prices are controlled for.
} 
Table 6: Robustness: Alternative Estimates of Firm-Product Markup

Panel A: Dependent variable is Firm-product-level markup

\begin{tabular}{|c|c|c|c|c|c|c|c|c|}
\hline \multirow{3}{*}{. } & \multicolumn{4}{|c|}{ Quantity-based data } & \multicolumn{4}{|c|}{ Alternative production function } \\
\hline & (1) & $(2)$ & $(3)$ & (4) & $(5)$ & (6) & $(7)$ & (8) \\
\hline & \multicolumn{2}{|c|}{ Ordinary Trade } & \multicolumn{2}{|c|}{ Processing Trade } & \multicolumn{2}{|c|}{ Ordinary Trade } & \multicolumn{2}{|c|}{ Processing Trade } \\
\hline & $\begin{array}{c}-4.667^{* *} \\
(2.009)\end{array}$ & $\begin{array}{c}-4.775^{* *} \\
(1.967)\end{array}$ & $\begin{array}{l}-3.166 \\
(3.100)\end{array}$ & $\begin{array}{c}-3.211 \\
(3.160)\end{array}$ & $\begin{array}{c}-2.383^{* *} \\
(1.096)\end{array}$ & $\begin{array}{c}-2.045^{* *} \\
(1.015)\end{array}$ & $\begin{array}{l}-0.039 \\
(1.149)\end{array}$ & $\begin{array}{l}-0.209 \\
(1.104)\end{array}$ \\
\hline Output tariff & $\begin{array}{c}1.499 \\
(1.215)\end{array}$ & $\begin{array}{c}1.173 \\
(1.308)\end{array}$ & $\begin{array}{c}1.822 \\
(1.751)\end{array}$ & $\begin{array}{c}1.523 \\
(1.865)\end{array}$ & $\begin{array}{c}0.466 \\
(0.723)\end{array}$ & $\begin{array}{c}0.421 \\
(0.679)\end{array}$ & $\begin{array}{l}-1.018 \\
(1.067)\end{array}$ & $\begin{array}{l}-0.715 \\
(0.978)\end{array}$ \\
\hline $\log (\mathrm{TFP})$ & & $\begin{array}{c}0.206^{* *} \\
(0.102)\end{array}$ & & $\begin{array}{c}0.039 \\
(0.123)\end{array}$ & & $\begin{array}{c}1.065^{* * *} \\
(0.049)\end{array}$ & & $\begin{array}{c}1.054^{* * *} \\
(0.040)\end{array}$ \\
\hline Observations & 170278 & 170278 & 56593 & 56593 & 606500 & 606500 & 182313 & 182313 \\
\hline R-squared & 0.877 & 0.877 & 0.869 & 0.869 & 0.843 & 0.845 & 0.847 & 0.850 \\
\hline \multicolumn{9}{|c|}{ Panel B: Dependent variable is Firm-product-level markup } \\
\hline & \multicolumn{4}{|c|}{ Pure exporters } & \multicolumn{4}{|c|}{ Market share } \\
\hline & $(1)$ & $(2)$ & $(3)$ & $(4)$ & $(5)$ & (6) & $(7)$ & $(8)$ \\
\hline & \multicolumn{2}{|c|}{ Ordinary Trade } & \multicolumn{2}{|c|}{ Processing Trade } & \multicolumn{2}{|c|}{ Ordinary Trade } & \multicolumn{2}{|c|}{ Processing Trade } \\
\hline Input tariff & $\begin{array}{c}-7.600 * * * \\
(2.826)\end{array}$ & $\begin{array}{c}-7.893^{* * *} \\
(2.675)\end{array}$ & $\begin{array}{c}1.145 \\
(2.477)\end{array}$ & $\begin{array}{c}0.872 \\
(2.447)\end{array}$ & $\begin{array}{c}-0.150 * * \\
(0.068)\end{array}$ & $\begin{array}{c}-0.147 * * \\
(0.067)\end{array}$ & $\begin{array}{l}-0.144 \\
(0.120)\end{array}$ & $\begin{array}{l}-0.141 \\
(0.122)\end{array}$ \\
\hline Output tariff & $\begin{array}{c}0.824 \\
(2.008)\end{array}$ & $\begin{array}{c}1.498 \\
(1.915)\end{array}$ & $\begin{array}{l}-0.190 \\
(1.872)\end{array}$ & $\begin{array}{c}0.277 \\
(1.807)\end{array}$ & $\begin{array}{c}0.007 \\
(0.036)\end{array}$ & $\begin{array}{c}0.006 \\
(0.037)\end{array}$ & $\begin{array}{l}-0.017 \\
(0.063)\end{array}$ & $\begin{array}{l}-0.024 \\
(0.064)\end{array}$ \\
\hline $\log (\mathrm{TFP})$ & & $\begin{array}{c}0.739 * * * \\
(0.138)\end{array}$ & & $\begin{array}{c}0.926^{* * * *} \\
(0.103)\end{array}$ & & $\begin{array}{c}0.002 \\
(0.002)\end{array}$ & & $\begin{array}{l}-0.002 \\
(0.003)\end{array}$ \\
\hline Observations & 100312 & 100312 & 53909 & 53909 & 575441 & 575441 & 167995 & 167995 \\
\hline R-squared & 0.893 & 0.894 & 0.898 & 0.900 & 0.941 & 0.941 & 0.898 & 0.898 \\
\hline Panel A and B: & & & & & & & & \\
\hline Other Firm-level Controls & $\mathrm{NO}$ & YES & $\mathrm{NO}$ & YES & $\mathrm{NO}$ & YES & $\mathrm{NO}$ & YES \\
\hline Industry-level Controls & $\mathrm{NO}$ & YES & $\mathrm{NO}$ & YES & $\mathrm{NO}$ & YES & $\mathrm{NO}$ & YES \\
\hline Year Fixed Effect & YES & YES & YES & YES & YES & YES & YES & YES \\
\hline Industry Fixed Effect & YES & YES & YES & YES & YES & YES & YES & YES \\
\hline Firm-Product Fixed Effect & YES & YES & YES & YES & YES & YES & YES & YES \\
\hline
\end{tabular}

Notes: ${ }^{* * *} \mathrm{p}<0.01,{ }^{*} \mathrm{p}<0.05,{ }^{*} \mathrm{p}<0.1$. Robust standard errors corrected by clustering variables at the industry-year level are in parentheses. Specifications 1-2 and 5-6 use ordinary trade observations and specifications 3-4 and 7-8 use processing trade observations. The measure of firm-product markup used in specifications 1-4 of panel is estimated based on physical quantity of output, in specifications 5-8 of panel A is estimated based on a different form of production function, in specifications 1-4 in panel B is estimated based on pure exporting firms, and in specifications 5-8 in panel B is estimated based on theoretical derivations. Other firm-level controls include firm size measured by employment, capital-labor ratio, and average wage; industry-level controls include industry average wage, capital intensity, share of college-trained employees, and the Herfindahl index at the 4-digit CIC industry level. When the method used to estimate markups changes, the solution to the system of equations also changes, thus yielding different sample sizes.

outputs. This alternative measure turns out to be correlated, at a high level of $79.58 \%$, with our benchmark measure generated by using deflated revenues. ${ }^{32}$ A high correlation between these two markup measures implies that using deflated sales instead of output quantities in the benchmark case would be acceptable. Columns 1-4 in Panel A of Table

\footnotetext{
${ }^{32}$ The correlation between firm-level markups generated by these two datasets is $74.95 \%$.
} 
6 report results for this alternative markup measure based on products' physical quantities. Similar to the benchmark case, we again distinguish between ordinary trade regime (columns 1 and 2) and processing trade regime (columns 3 and 4): a reduction in input tariffs significantly increases markups for ordinary trade observations, while a similar impact is absent for processing trade observations. As for underlying mechanisms, we replicate all previous tests for known channels of import intensity and marginal costs. All benchmark results hold when firm-product markup measures based on physical quantities of output are used as proxies in all regressions (see Table A.3 and A.4 in the Appendix). Firms with higher import-intensity are more affected by input-tariff reductions, and the main channel of markup adjustment is through marginal costs.

Our benchmark results are also robust to different production function specifications. In the benchmark, we use a translog production function of labor, capital, materials, and their second-order interaction terms. The triple interaction term, $l_{f t} k_{f t} m_{f t}$, is ignored due to computational complexities. But here we add back the triple interaction term and re-calculate firm-product markups. This new markup measure is highly correlated with its benchmark counterpart at a level of $81.74 \%{ }^{33}$ Columns $5-8$ in Panel A of Table 6 present contrasting results of ordinary traded (columns 5 and 6 ) versus those of processing trades (columns 7 and 8): a reduction in input tariffs significantly increases markups for ordinary trade observations, while this is not so for processing trade observations.

An important assumption in De Loecker et al. (2016) is that input shares must sum up to one across all products. Unfortunately, this assumption does not hold in our benchmark since most firms in our matched sample export only a portion of their products. So, we replace this assumption with the one made by Kee and Tang (2016): the share of inputs allocated to export production is proportional to the share of exports in total sales. In other words, summing up the input share spent in each export product is equal to the ratio of exports to total sales. In order to show that this assumption replacement is not driving of our results, we limit our sample to firms who export all of their products (or pure exporters). This subsample accounts for approximately $16 \%$ of the observations in our base sample, and in this subsample we can safely use the original assumption by De Loecker et al. (2016). Our benchmark results still preserve as can be seen from columns 1 to 4 in Panel B of Table 6.

Despite robustness checks conducted earlier, one may still have doubts about other unexploited limitations to our empirical strategy. Therefore, we consult our model for a theoretical measure of firm-product markups based on observable variables. According to equation (11), the firm-product markup can be written as a function of the firm-product market share and the elasticity of substitution. We calculate market shares within the HS 4-digit industry category, and allow the substitution elasticity $\sigma_{i}$ to vary across HS

\footnotetext{
${ }^{33}$ The correlation between firm-level markups generated by these two production functions is $96.95 \%$.
} 
2-digit industries as estimated by Broda and Weinstein (2006). ${ }^{34}$ Columns 5 to 8 in Panel B of Table 6 tell us that the hypothesized effects hold for ordinary trades but not for processing trades. ${ }^{35}$

Table A.5 in the Appendix conducts extra tests with the model-based measure of firm-product markups. In columns 1 to 4 of Table A.5, we calculate market shares within the HS 2-digit code instead of the HS 4-digit code. In columns 5 to 8 of Table A.5, we set $\sigma=6$ and reproduce firm-product markups using equation (11). ${ }^{36}$ Once again, there are significant impacts of input-tariff cuts on firm-product markups for the ordinary trade sample (columns 1 and 2, and 5 and 6), and no such effects exist in the processing trade sample (columns 3 and 4 , and 7 and 8).

\subsection{Difference estimator}

This subsection tries an alternative econometric approach, namely the difference estimators with lags ranging from 1 year to 5 years. As mentioned earlier, we retain controls for changes in firm-level and industry-level characteristics as well as year fixed effects. Unlike aforementioned regressions, we remove firm-product and industry fixed effects.

Table 7: The Effect of Tariffs on Markups: First-Difference and Long-Difference

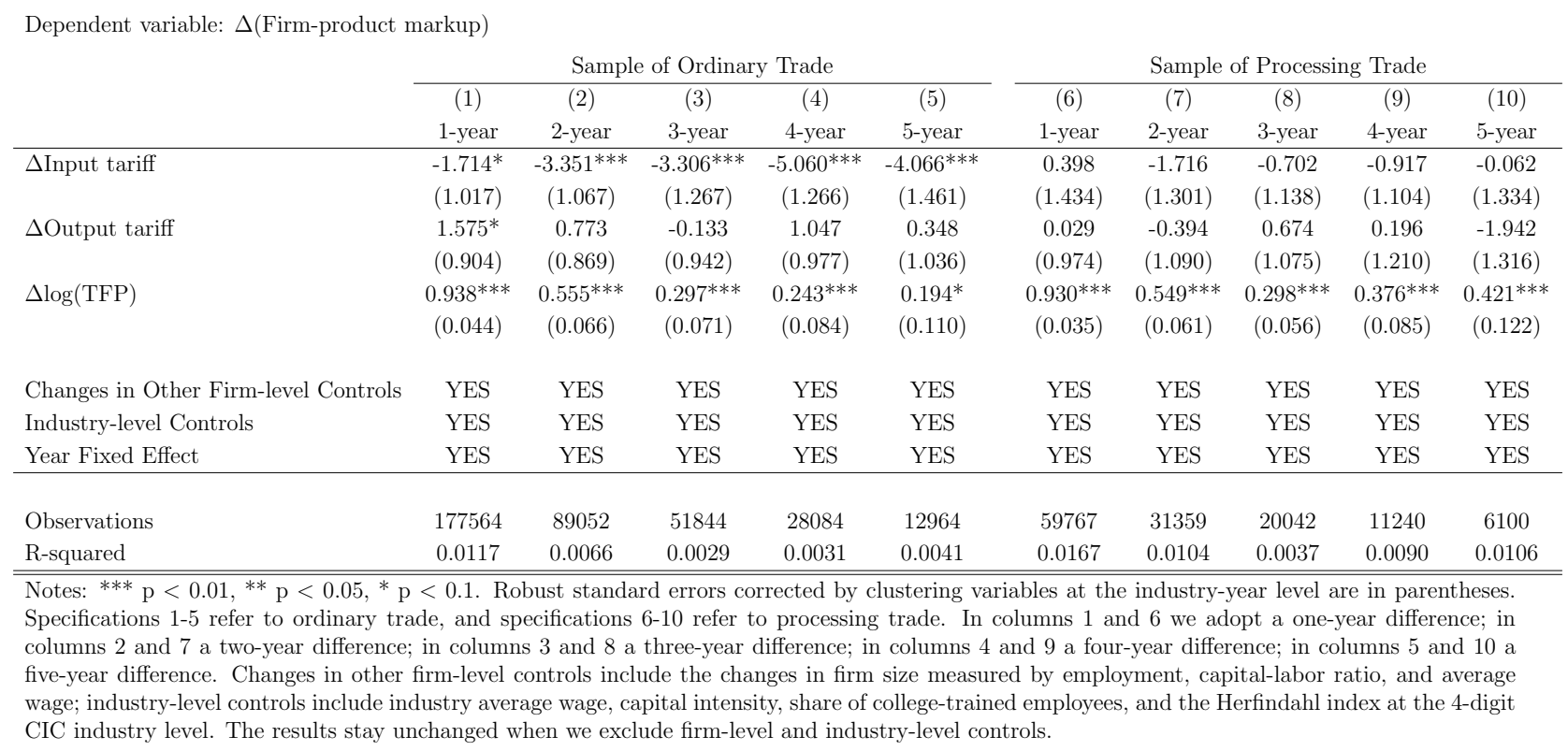

\footnotetext{
${ }^{34}$ Broda and Weinstein (2006) estimate the elasticity of substitution for disaggregated categories. They report the average and median elasticity to take values of 7.5 and 2.8 , respectively. We aggregate their estimates to the HS 2-digit level, and then merge the aggregates with our base sample.

${ }^{35}$ This model-based firm-product markup correlates with our benchmark markup by a degree of $8.52 \%$.

${ }^{36}$ The related literature, such as Anderson and van Wincoop (2004) and Eaton and Kortum (2002), suggests that a reasonable range for $\sigma$ falls in the range of $[5,10]$
} 
The results of the difference estimation are reported in Table 7 . We adopt firstdifference and long-difference estimators to evaluate the impact of tariff changes on markup adjustment. The advantage of this approach is that differencing removes the latent heterogeneity in the model, and hence addresses the omitted variables problem in panel data. Our previous results still hold when difference estimators with various lagged intervals are employed. To get a sense of the magnitude, a $1 \%$ reduction in input tariffs would lead to a $2-5 \%$ increase in markups for ordinary trade observations. Again, the input-tariff effects do not operate for processing trade observations.

Table 8: The Effect of Tariffs on Markups: Instrumental Variable Estimation

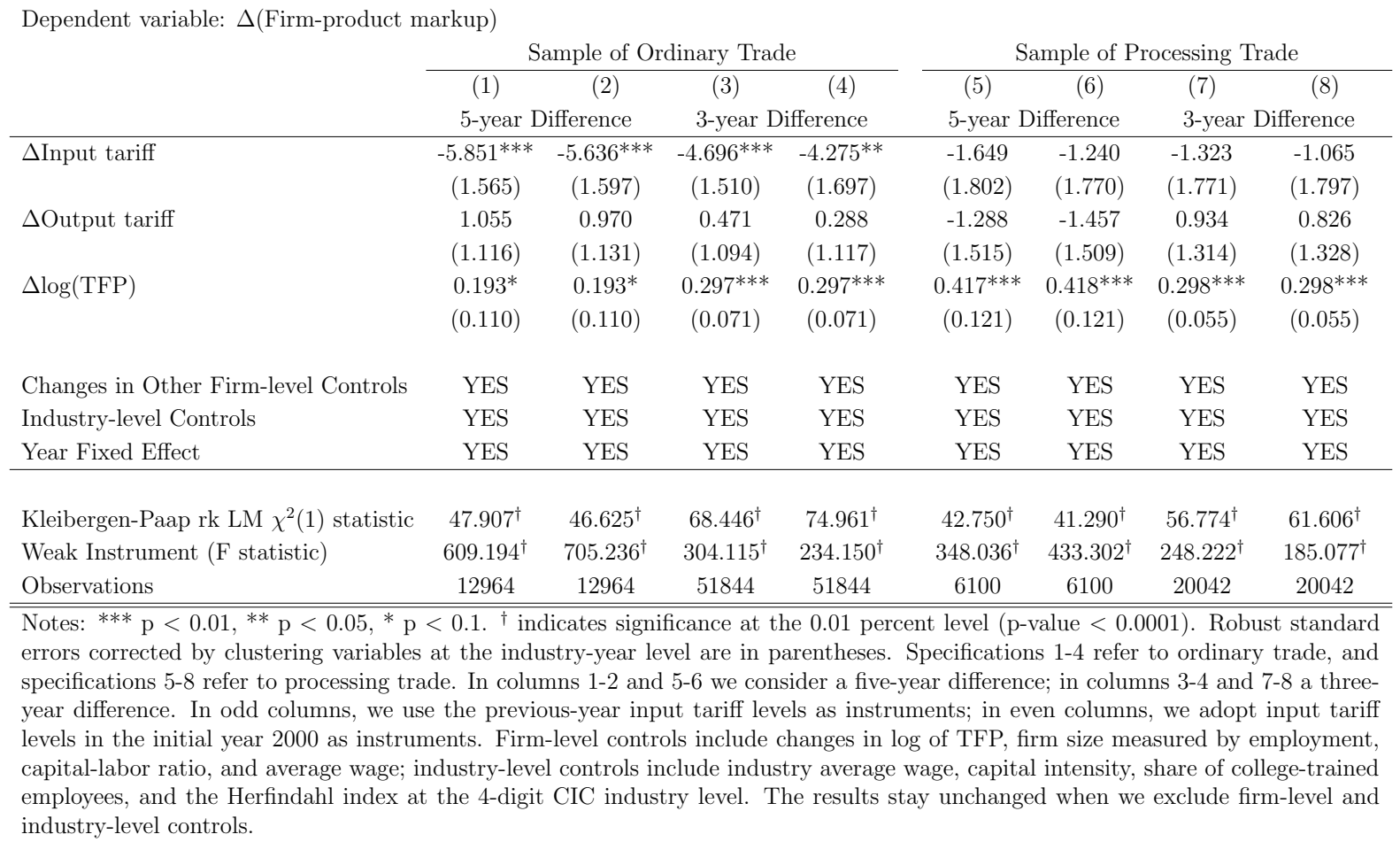

\subsection{Endogeneity}

This subsection discusses the potential endogeneity issue of tariffs, as it may bias our estimation with firm fixed-effects models according to Amiti and Konings (2007). In our baseline regressions, we have already included industry and firm-product fixed effects, and, from an individual firm's perspective, tariff reductions should be exogenous. Nevertheless, we relax the assumption of exogenous trade liberalization in China from 2000 to 2006, since it is possible that tariff levels are set subject to lobbying efforts. If the political pressure is only industry specific but time invariant, then controlling for industry fixed effects alleviate this endogeneity concern. If otherwise, the political pressure 
varies with time, we have to find instrument variables for input tariffs, and the results are shown in Table 8. Following Amiti and Konings (2007), all IV specifications in Table 8 use difference estimators. Note that only results for 3-year and 5-year differences are reported, as finding instruments to measure the changes in tariffs is much easier than finding instruments to measure the levels of tariffs.

A frequently used instrument to establish tariff changes is past tariff levels (Goldberg and Pavcnik, 2005). Given that China entered the WTO in 2001 and started to reduce tariffs significantly since then, we use two sets of variables - input-tariff levels in the preceding year and in the initial year of 2000 - as instruments for input-tariff variations.

To assure the validity of our instruments, we construct two joint tests. The first statistic is derived from a Langrange-Multiplier (LM) test, which diagnoses underidentification using the Kleibergen and Paap (2006) rk statistic. A usual canonical correlation likelihood ratio test (Anderson, 1984) is inappropriate because the error term in our econometric model is heteroskedastic. ${ }^{37}$ The Kleibergen and Paap (2006) rk statistic tests whether an instrument is relevant to the endogenous variable. The null hypothesis of an underidentified model is rejected at the $0.1 \%$ significance level.

The second statistic is derived from the Kleibergen and Paap (2006) Wald test, which checks whether an instrument is weakly correlated with the endogenous variable. The Kleibergen and Paap (2006) Wald F-statistics provide strong evidence to reject the null hypothesis: the first stage is weakly identified at a highly significant level. That is to say, in all specifications, our instrumental variables provide a good fit in the first stage, and can be considered as valid instruments.

As before, results shown in Table 8 conform to our previous findings: for the ordinary trade sample, input-tariff reductions significantly raise firm-product markups, while this pattern is absent for the processing trade sample.

\section{Robustness}

This section further corroborates our main results by conducting more robustness checks, such as adopting firm-level markup estimates, using firm-specific and product-specific tariff measures, adding export tariffs, dropping outliers by various criteria, introducing exchange rate shocks, and differentiating between firm ownership types.

\footnotetext{
${ }^{37}$ In all specifications, the Cragg-Donald Wald F statistics are also well above their corresponding critical values listed in Stock and Yogo (2005). However, we choose not to report since these critical values are for i.i.d. errors while the error term in our econometric model is assumed to be heteroskedastic.
} 


\subsection{Effect of tariffs on firm-level markup}

In the benchmark case, we measure markups at the firm-product level by merging the firm-level NBSC survey data and the transaction-level customs data. Here, we use the firm-level NBSC survey data alone to estimate corresponding markups at the firm level. See Appendix B for a description of estimation procedures. Regression results based on this firm-level markup measure are reported in columns 1 and 2 of Table 9. Similarly, we can measure firm-level markups using different methodologies just as what we did for firm-product level markups in Section 5.3. In particular, columns 3 and 4 of Table 9 use physical quantities instead of deflated revenues (see Appendix C for more details), columns 5 and 6 of Table 9 add a triple interaction term to the translog production function, and columns 7 and 8 of Table 9 investigate pure exporters.

In each specification, we make a distinction between ordinary trade regime (odd columns) and processing trade regime (even columns). Table 9 presents similar results to the benchmark case: input-tariff reductions increase firm-level markups for ordinary trade observations but not for processing trade observations. ${ }^{38}$

\subsection{Firm-specific and product-specific tariffs}

Since our model describes a firm adjusting its markups on input-tariff reductions, computing firm-level tariffs may be better at capturing information on the exact bundle of inputs imported by each individual firm. Firm-level tariff measures provide high resolution to firm-specific intensive-margin effects of tariff reduction (Fan, Li and Yeaple, 2015), complementing our previous results using industry-level input tariffs.

We follow $\mathrm{Yu}$ (2015) to compute firm-level tariffs. An exporter can engage in both processing imports (denoted by $P$ ) and ordinary imports (denoted by $O$ ). Define $M=$ $O \cup P$ as the set of the exporter's total imports. Since processing imports are duty-free in China, the firm- $i$-specific input tariff at time $t$ can be constructed as follows:

$$
F I T_{i t}=\sum_{k \in O} \frac{m_{i, t}^{k}}{\sum_{j \in M} m_{i, t}^{j}} \tau_{t}^{k}
$$

where $m_{i, t}^{k}$ is firm $i$ 's imports of an ordinary product $k$ in year $t$, which would be inversely associated with its corresponding tariff $\tau_{t}^{k}$. To avoid this endogeneity problem

\footnotetext{
${ }^{38}$ Amiti and Konings (2007) show that, after a reduction in output tariffs, firms would face stronger competition from imported final goods. Following their prediction, coefficients on output tariffs in Table 9 are indeed significantly positive for ordinary traders. Different from other tables where markups are defined for export products, markups in Table 9 are defined for domestic products. When competition is intensified due to output-tariff cuts, domestic-market-oriented firms have no choice but to lower markups so that they can hold onto some market shares.
} 
Table 9: Robustness: The Effect of Tariffs on Firm-Level Markups

\begin{tabular}{|c|c|c|c|c|c|c|c|c|}
\hline \multicolumn{9}{|c|}{ Dependent variable: Four estimates of firm-level markup } \\
\hline & OT & $\mathrm{PT}$ & OT & PT & OT & PT & OT & PT \\
\hline & (1) & $(2)$ & (3) & $(4)$ & $(5)$ & (6) & (7) & $(8)$ \\
\hline & \multicolumn{2}{|c|}{ Benchmark } & \multicolumn{2}{|c|}{ Quantity-based data } & \multicolumn{2}{|c|}{ Alternative function } & \multicolumn{2}{|c|}{ Pure exporters } \\
\hline \multirow[t]{2}{*}{ Input tariff } & $-0.496^{* * *}$ & -0.135 & $-1.399 * * *$ & -0.746 & $-0.348^{* *}$ & -0.164 & $-1.019^{* * *}$ & -0.037 \\
\hline & $(0.170)$ & $(0.353)$ & $(0.274)$ & $(0.563)$ & $(0.174)$ & $(0.354)$ & $(0.270)$ & $(0.415)$ \\
\hline \multirow[t]{2}{*}{ Output tariff } & $0.210^{* *}$ & 0.095 & $0.356^{* *}$ & -0.182 & $0.177^{*}$ & 0.091 & $0.390^{* *}$ & 0.115 \\
\hline & $(0.097)$ & $(0.141)$ & $(0.154)$ & $(0.325)$ & $(0.099)$ & $(0.135)$ & $(0.186)$ & $(0.156)$ \\
\hline \multirow[t]{2}{*}{$\log (\mathrm{TFP})$} & $0.890^{* * *}$ & $0.841^{* * *}$ & $0.501^{* * *}$ & $0.564^{* * *}$ & $0.896^{* * *}$ & $0.827^{* * *}$ & $0.910^{* * *}$ & $0.837 * * *$ \\
\hline & $(0.012)$ & $(0.021)$ & $(0.039)$ & $(0.088)$ & $(0.012)$ & $(0.022)$ & $(0.040)$ & $(0.032)$ \\
\hline Other Firm-level Controls & YES & YES & YES & YES & YES & YES & YES & YES \\
\hline Industry-level Controls & YES & YES & YES & YES & YES & YES & YES & YES \\
\hline Year Fixed Effect & YES & YES & YES & YES & YES & YES & YES & YES \\
\hline Industry Fixed Effect & YES & YES & YES & YES & YES & YES & YES & YES \\
\hline Firm-Product Fixed Effect & YES & YES & YES & YES & YES & YES & YES & YES \\
\hline Observations & 126260 & 12872 & 33538 & 3842 & 126259 & 12872 & 22340 & 7127 \\
\hline R-squared & 0.939 & 0.945 & 0.892 & 0.924 & 0.940 & 0.945 & 0.949 & 0.936 \\
\hline \multicolumn{9}{|c|}{$\begin{array}{l}\text { Notes: OT and PT stand for Ordinary Trade and Processing trade, respectively. }{ }^{* * *} \mathrm{p}<0.01,{ }^{* *} \mathrm{p}<0.05,{ }^{*} \mathrm{p}<0.1 \text {. Robust } \\
\text { standard errors corrected by clustering variables at the industry-year level are in parentheses. Odd columns correspond to } \\
\text { ordinary trade observations, while even columns refer to processing trade observations. Other firm-level controls include } \\
\text { firm size measured by employment, capital-labor ratio, and average wage; industry-level controls include industry average } \\
\text { wage, capital intensity, share of college-trained employees, and the Herfindahl index at the } 4 \text {-digit CIC industry level. The } \\
\text { results stay unchanged when we exclude firm-level and industry-level controls. }\end{array}$} \\
\hline
\end{tabular}

well known in constructing the weighted tariff, we also calculate an unweighted average of firm-specific input tariffs by setting the weight $m_{i, t}^{k}$ to 1 .

In columns 1-4 of Table 10, we present results of regressing markups on firm-specific tariffs for ordinary trades. Columns 1 and 2 and columns 3 and 4 refer to estimations for weighted and unweighted average tariffs, respectively. We conclude that a $1 \%$ decrease in firm-specific input tariff would lead to a $0.4-0.6 \%$ increase in firm-product markups for ordinary trades. As anticipated, firm-level input tariffs have smaller effects than industrylevel counterparts (columns 1-4 in Table 10 vs. columns 1 and 2 in Table 2). Because some firms may use intermediate inputs that are imported by other firms within the same industry, and such intermediary activities would be captured by industry-level tariffs but not by firm-specific input tariffs. ${ }^{39}$

Since HS6 product classification directly maps into China's IO table, we are capable of computing input and output tariffs at the HS6 product level. We then merge HS6 product-level tariffs with firm-product markups. The results of regressing markups on HS6-product-specific tariffs are reported in columns 5-8 in Table 10: the input-tariff

\footnotetext{
${ }^{39}$ This also explains why the results with firm-specific input tariffs are only significant at approximately the $20 \%$ level, if variables are clustered at the industry-year or the firm level.
} 
effects apply only to firms under the ordinary trade regime.

Table 10: Robustness: Firm-Specific and HS6-Product-Specific Tariffs

Dependent variable: Firm-product markup

\begin{tabular}{|c|c|c|c|c|c|c|c|c|}
\hline & \multicolumn{4}{|c|}{ Firm-level average tariff } & \multicolumn{4}{|c|}{ Industry tariff at the HS 6-digit level } \\
\hline & (1) & $(2)$ & $(3)$ & (4) & (5) & $(6)$ & (7) & (8) \\
\hline & \multicolumn{2}{|c|}{ Weighted tariff } & \multicolumn{2}{|c|}{ Unweighted tariff } & \multicolumn{2}{|c|}{ Ordinary trade } & \multicolumn{2}{|c|}{ Processing trade } \\
\hline Input tariff & $\begin{array}{c}-0.397^{* *} \\
(0.159)\end{array}$ & $\begin{array}{c}-0.373^{* *} \\
(0.158)\end{array}$ & $\begin{array}{c}-0.542^{* *} \\
(0.214)\end{array}$ & $\begin{array}{c}-0.558^{* * *} \\
(0.213)\end{array}$ & $\begin{array}{c}-2.460 * * \\
(1.056)\end{array}$ & $\begin{array}{c}-2.248^{* *} \\
(1.018)\end{array}$ & $\begin{array}{l}-1.859 \\
(1.200)\end{array}$ & $\begin{array}{l}-1.792 \\
(1.185)\end{array}$ \\
\hline Output tariff & & & & & $\begin{array}{c}0.694 \\
(0.731)\end{array}$ & $\begin{array}{c}0.764 \\
(0.701)\end{array}$ & $\begin{array}{l}-0.900 \\
(0.901)\end{array}$ & $\begin{array}{l}-0.662 \\
(0.901)\end{array}$ \\
\hline $\log (\mathrm{TFP})$ & & $\begin{array}{c}0.983^{* * *} \\
(0.033)\end{array}$ & & $\begin{array}{c}0.984^{* * *} \\
(0.033)\end{array}$ & & $\begin{array}{c}0.909^{* * *} \\
(0.051)\end{array}$ & & $\begin{array}{c}0.954^{* * *} \\
(0.054)\end{array}$ \\
\hline Other Firm-level controls & NO & YES & NO & YES & NO & YES & NO & YES \\
\hline Industry-level controls & $\mathrm{NO}$ & YES & NO & YES & NO & YES & $\mathrm{NO}$ & YES \\
\hline Year Fixed Effect & YES & YES & YES & YES & YES & YES & YES & YES \\
\hline Industry Fixed Effect & YES & YES & YES & YES & YES & YES & YES & YES \\
\hline Firm-Product Fixed Effect & YES & YES & YES & YES & YES & YES & YES & YES \\
\hline Observations & 287394 & 287394 & 287394 & 287394 & 560033 & 560033 & 164356 & 164356 \\
\hline R-squared & 0.895 & 0.896 & 0.895 & 0.896 & 0.876 & 0.878 & 0.860 & 0.862 \\
\hline
\end{tabular}

Notes: $* * * \mathrm{p}<0.01,{ }^{* *} \mathrm{p}<0.05, * \mathrm{p}<0.1$. Specifications $1-6$ use ordinary trade observations and specifications 7-8 use processing trade observations. Specifications 1-4 adopt firm-specific weighted and unweighted tariffs according to Yu (2015), and specifications 5-8 adopt industry-level input and output tariff at the HS6 level. Other firm-level controls include firm size measured by employment, capital-labor ratio, and average wage; industry-level controls include industry average wage, capital intensity, share of college-trained employees, and the Herfindahl index at the 4-digit CIC industry level. For columns 1-4, Robust standard errors reported in parentheses are not clustered (if we cluster variables at the industry-year level or firm level in these columns, the results become significant only at approximately the $20 \%$ level; for columns $5-8$, robust standard errors corrected by clustering variables at the industry-year level are in parentheses.

\subsection{Sensitivity to export tariffs, outliers, exchange rates, and firm ownership types}

Presumably, trade policies imposed by an exporter's destination countries could also affect the exporter's firm-product markups of its exported goods. To address this issue, we would like to control for export tariffs in each industry $k$ at any time $t$. The measure of export tariffs is constructed in three steps. First, for each product at the HS 6-digit level, we calculate a weighted average export tariff with the product's export value to the corresponding country being the weight. Second, for each IO 3-digit industry, we compute a simple average export tariff across all products in that industry. Third, we map IO 3-digit industries into CIC 4-digit industries. Results shown in columns 1-4 if Table 11 suggest that our benchmark results stay unchanged after controlling for export tariffs. 
Then, in Table 11, we dispel misgivings about potential effects of the outliers. Columns 5-8 repeat the benchmark exercises after dropping observations ranked top and bottom 2.5 percentage according to their firm-product markups. ${ }^{40}$ The results are consistent with our previous findings.

Table 11: Robustness: Sensitivity to Export Tariffs and Outliers

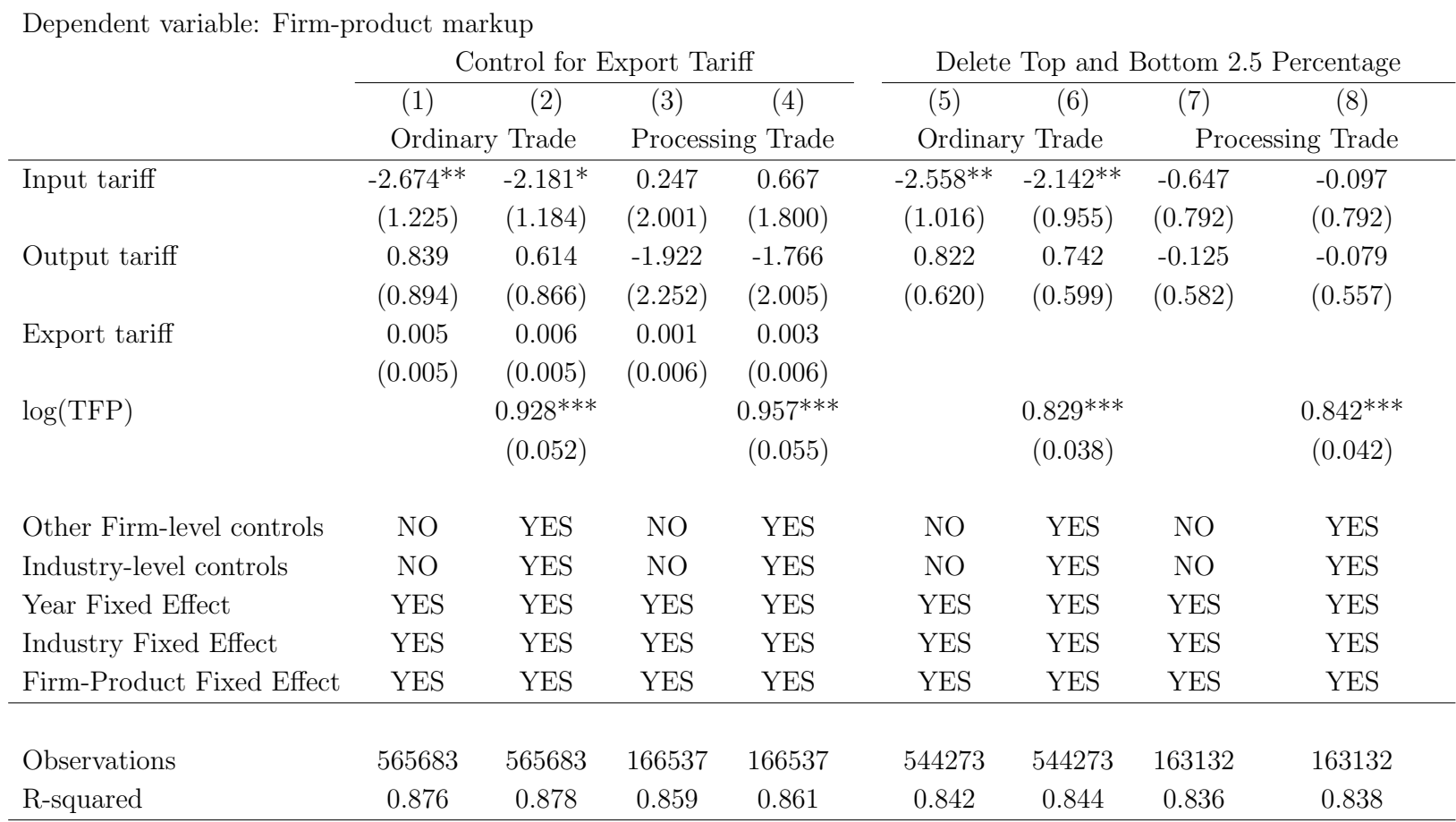

Notes: ${ }^{* * *} \mathrm{p}<0.01,{ }^{* *} \mathrm{p}<0.05,{ }^{*} \mathrm{p}<0.1$. Robust standard errors corrected by clustering variables at the industryyear level are in parentheses. Specifications 1-2 and 5-6 use ordinary trade observations, and specifications 3-4 and 7-8 use processing trade observations. In specifications 1-4 we control for export tariffs; in specifications 5-8 we delete observations that fall into the top and bottom 2.5 percentile of markups. Other firm-level controls include firm size measured by employment, capital-labor ratio, and average wage; industry-level controls include industry average wage, capital intensity, share of college-trained employees, and the Herfindahl index at the 4-digit CIC industry level.

Next, we show that our results are not driven by movements in exchange rates between the RMB and other currencies. Since the RMB experienced a substantial appreciation in late 2005, we exclude observations from the period of 2005-2006, and conduct robustness checks based on the pre-appreciation period of 2000-2004. The results are reported in columns 1-4 of Table 12. Again our main findings stay unchanged.

Lastly, one might be concerned about the role played by China's SOEs. ${ }^{41}$ In general, the Chinese government may give SOEs more favorable treatments than domestic private firms. In addition, some SOEs may be employment- and/or size-oriented rather than purely profit-oriented. Although the baseline regressions have already controlled for firmsize effect, this ownership issue is never explicitly addressed and it could potentially affect

\footnotetext{
${ }^{40}$ Extending the range of outliers to top and bottom 5 percentage would not change our results either.

${ }^{41}$ Also, there are many foreign-invested companies and joint ventures in China.
} 
SOEs' behavior of markup adjustments. For this reason, we re-conduct our baseline regressions for ordinary and processing trades with firm-ownership fixed effects (measured by the firm's registered type in China). ${ }^{42}$ These results are reported in columns $5-8$ of Table 12. Our main findings are robust to adding ownership variables.

Table 12: Robustness: Sensitivity to Exchange Rates and Firm Ownership Types

\begin{tabular}{|c|c|c|c|c|c|c|c|c|}
\hline \multicolumn{9}{|c|}{ ependent variable: Firm-product markup } \\
\hline & (1) & $(2)$ & $(3)$ & (4) & $(5)$ & (6) & (7) & $(8)$ \\
\hline & \multicolumn{2}{|c|}{ Ordinary Trade } & \multicolumn{2}{|c|}{ Processing Trade } & \multicolumn{2}{|c|}{ Ordinary Trade } & \multicolumn{2}{|c|}{ Processing Trade } \\
\hline \multirow[t]{2}{*}{ Input tariff } & $-2.259^{*}$ & $-2.368^{*}$ & -0.579 & -0.554 & $-2.859^{* *}$ & $-2.446^{* *}$ & 0.156 & 0.538 \\
\hline & $(1.266)$ & $(1.222)$ & $(1.278)$ & $(1.207)$ & $(1.223)$ & $(1.177)$ & $(2.018)$ & $(1.819)$ \\
\hline \multirow[t]{2}{*}{ Output tariff } & 1.038 & 1.072 & 0.553 & 0.585 & 0.862 & 0.736 & -1.749 & -1.506 \\
\hline & $(1.034)$ & $(1.006)$ & $(0.871)$ & $(0.864)$ & $(0.867)$ & $(0.845)$ & $(2.231)$ & $(1.989)$ \\
\hline \multirow[t]{2}{*}{$\log (\mathrm{TFP})$} & & $0.902^{* * *}$ & & $0.864^{* * *}$ & & $0.918^{* * *}$ & & $0.950^{* * *}$ \\
\hline & & $(0.083)$ & & $(0.062)$ & & $(0.050)$ & & $(0.055)$ \\
\hline Other Firm-level controls & $\mathrm{NO}$ & YES & NO & YES & NO & YES & NO & YES \\
\hline Industry-level controls & $\mathrm{NO}$ & YES & NO & YES & NO & YES & NO & YES \\
\hline Year Fixed Effect & YES & YES & YES & YES & YES & YES & YES & YES \\
\hline Industry Fixed Effect & YES & YES & YES & YES & YES & YES & YES & YES \\
\hline Firm-Product Fixed Effect & YES & YES & YES & YES & YES & YES & YES & YES \\
\hline Firm Ownership Type Fixed Effect & NO & NO & NO & NO & YES & YES & YES & YES \\
\hline Observations & 306948 & 306948 & 106148 & 106148 & 575824 & 575824 & 168813 & 168813 \\
\hline R-squared & 0.892 & 0.893 & 0.881 & 0.883 & 0.876 & 0.878 & 0.859 & 0.862 \\
\hline
\end{tabular}

Notes: ${ }^{* * *} \mathrm{p}<0.01,{ }^{* *} \mathrm{p}<0.05,{ }^{*} \mathrm{p}<0.1$. Robust standard errors corrected by clustering variables at the industry-year level are in parentheses. Specifications 1-2 and 5-6 use ordinary trade observations, and specifications 3-4 and 7-8 use processing trade observations. Specifications 1-4 conduct sensitivity analysis with respect to exchange rate fluctuations, whereas specifications 5-8 test the sensitivity of our results to different ownership types. Other firm-level controls include firm size measured by employment, capital-labor ratio, and average wage; industry-level controls include industry average wage, capital intensity, share of college-trained employees, and the Herfindahl index at the 4-digit CIC industry level.

\section{Conclusion}

This paper uncovers patterns of markup adjustments under trade liberalization. The implication strongly suggests that better accessibility to imported intermediate inputs can substantially increase firms' market powers. We first document stylized facts regarding the relationship between China's trade liberalization and markup adjustments by firms in two distinct trade regimes. We then devise an econometric model from a simple analytical framework with variable markups and imported intermediates. After estimating this model based on Chinese production and customs data during China's

\footnotetext{
${ }^{42}$ Types of ownership are SOEs, multinational companies, joint ventures, domestic private firms, collective enterprises, etc.
} 
WTO accession period, we find strong and robust evidence that ordinary trade firms, who are subject to import tariffs, would significantly raise their product markups upon input-tariff reductions, while processing trade firms, who are duty-free, do not have such reactions. The underlying mechanisms are also investigated empirically, and it turns out the marginal-cost and import-dependence channels play important roles in linking tariffs and markups.

Our study contributes to (1) a vibrant literature that examines the impact of trade reforms on the efficient allocation of resources among trading firms, (2) the literature that links improved access to imported intermediate inputs to superior firm performance, and (3) the literature that explores differences between the response of ordinary trade firms versus the response of processing trade firms to trade policy changes. It would be interesting to further assess resource reallocation and markup adjustment under trade liberalization across core versus peripheral products within multi-product firms. It would also be fruitful to adopt a structural estimation that combines markup and quality adjustments in a dynamic setup of firm behaviors. Last but not least, since Edmond, Midrigan and $\mathrm{Xu}$ (2015) argue the distribution of markups to be an important determinant of social welfare, another promising field for future research to explore is the distributional outcome of markup adjustments. 


\section{References}

Amiti, Mary, and Amit K. Khandelwal. 2013. "Import Competition and Quality Upgrading." The Review of Economics and Statistics, 95(2): 476-490.

Amiti, Mary, and Jozef Konings. 2007. "Trade Liberalization, Intermediate Inputs, and Productivity: Evidence from Indonesia." American Economic Review, 97(5): 16111638.

Amiti, Mary, Oleg Itskhoki, and Jozef Konings. 2014. "Importers, Exporters, and Exchange Rate Disconnect." American Economic Review, 104(7): 1942-78.

Anderson, James E., and Eric van Wincoop. 2004. "Trade Costs." Journal of Economic Literature, 42(3): 691-751.

Anderson, T. W. 1984. An introduction to multivariate statistical analysis. Wiley series in probability and mathematical statistics. 2 ed., New York:Wiley. T.W. Anderson; ;25 cm; Includes index; Bibliography: p. 643-665.

Arkolakis, Costas, Arnaud Costinot, Dave Donaldson, and Andrés RodríguezClare. 2015. "The Elusive Pro-Competitive Effects of Trade."

Bas, Maria. 2012. "Input-trade liberalization and firm export decisions: Evidence from Argentina." Journal of Development Economics, 97(2): 481-493.

Bas, Maria, and Vanessa Strauss-Kahn. 2015. "Input-trade liberalization, export prices and quality upgrading." Journal of International Economics, 95(2): 250-262.

Bernard, Andrew B., Stephen J. Redding, and Peter K. Schott. 2010. "MultipleProduct Firms and Product Switching." American Economic Review, 100(1): 70-97.

Brandt, Loren, Johannes Van Biesebroeck, and Yifan Zhang. 2012. "Creative Accounting or Creative Destruction? Firm-level Productivity Growth in Chinese Manufacturing." Journal of Development Economics, 97(2): 339-351.

Broda, Christian, and David E. Weinstein. 2006. "Globalization and the Gains From Variety." The Quarterly Journal of Economics, 121(2): 541-585.

Cai, Hongbin, and Qiao Liu. 2009. "Competition and Corporate Tax Avoidance: Evidence from Chinese Industrial Firms." Economic Journal, 119(537): 764-795.

Chen, Natalie, Jean Imbs, and Andrew Scott. 2009. "The dynamics of trade and competition." Journal of International Economics, 77(1): 50-62.

De Loecker, Jan, and Frederic Warzynski. 2012. "Markups and Firm-Level Export Status." American Economic Review, 102(6): 2437-71. 
De Loecker, Jan, and Pinelopi Koujianou Goldberg. 2014. "Firm Performance in a Global Market." Annual Review of Economics, 6(1): 201-227.

De Loecker, Jan, Pinelopi K. Goldberg, Amit K. Khandelwal, and Nina Pavcnik. 2016. "Prices, Markups and Trade Reform." Econometrica, 84(2): 445-510.

Eaton, Jonathan, and Samuel Kortum. 2002. "Technology, geography, and trade." Econometrica, 70(5): 1741-1779.

Edmond, Chris, Virgiliu Midrigan, and Daniel Yi Xu. 2015. "Competition, Markups, and the Gains from International Trade." American Economic Review, 105(10): 3183-3221.

Fan, Haichao, Edwin L.-C. Lai, and Yao Amber Li. 2015. "Credit Constraints, Quality, and Export Prices: Theory and Evidence from China." Journal of Comparative Economics, 43(2): 390-416.

Fan, Haichao, Yao Amber Li, and Stephen R. Yeaple. 2015. "Trade Liberalization, Quality, and Export Prices." Review of Economics and Statistics, 97(5): 1033-1051.

Fan, Haichao, Yao Amber Li, and Stephen R. Yeaple. 2016. "On the Relationship Between Quality and Productivity: Evidence from China's Accession to the WTO." Working Paper.

Goldberg, Pinelopi Koujianou, Amit Kumar Khandelwal, Nina Pavcnik, and Petia Topalova. 2010. "Imported Intermediate Inputs and Domestic Product Growth: Evidence from India." The Quarterly Journal of Economics, 125(4): 1727-1767.

Goldberg, Pinelopi Koujianou, and Nina Pavcnik. 2005. "Trade, wages, and the political economy of trade protection: evidence from the Colombian trade reforms." Journal of International Economics, 66(1): 75-105.

Gopinath, Gita, and Brent Neiman. 2014. "Trade Adjustment and Productivity in Large Crises." American Economic Review, 104(3): 793-831.

Halpern, László, Miklós Koren, and Adam Szeidl. 2015. "Imported Inputs and Productivity." American Economic Review, 105(12): 3660-3703.

Harrison, Ann. 1994. "Productivity, Imperfect Competition and Trade Reforms: Theory and Evidence." Journal of International Economics, 36: 53-73.

Johnson, Robert, and Guillermo Noguera. 2012. "Fragmentation and trade in value added over four decades." NBER Working Paper No.18186. 
Kee, Hiau Looi, and Heiwai Tang. 2016. "Domestic Value Added in Exports: Theory and Firm Evidence from China." The American Economic Review, 106(6): 1402-36.

Kleibergen, Frank, and Richard Paap. 2006. "Generalized reduced rank tests using the singular value decomposition." Journal of Econometrics, 133(1): 97-126.

Konings, Jozef, Patrick Van Cayseele, and Frederic Warzynski. 2001. "The dynamics of industrial mark-ups in two small open economies: does national competition policy matter?" International Journal of Industrial Organization, 19(5): 841-859.

Koopman, Robert, Zhi Wang, and Shang-Jin Wei. 2014. "Tracing Value-Added and Double Counting in Gross Exports." American Economic Review, 104(2): 459-494.

Levinsohn, James. 1993. "Testing the imports-as-market-discipline hypothesis." Journal of International Economics, 35(1): 1-22.

Levinsohn, James, and Amil Petrin. 2003. "Estimating production functions using Inputs to Control for Unobservables." Review of Economic Studies, 70: 317-341.

Lu, Yi, and Linhui Yu. 2015. "Trade Liberalization and Markup Dispersion: Evidence from China's WTO Accession." American Economic Journal: Applied Economics, 7(4): 221-53.

Manova, Kalina, and Zhihong Yu. forthcoming. "Firms and Credit Constraints along the Global Value Chain: Processing Trade in China." Journal of Intertional Economics.

Simonovska, Ina. 2015. "Income Differences and Prices of Tradables: Insights from an Online Retailer." Review of Economic Studies, 82(4): 1612-1656.

Stock, James H., and Motohiro Yogo. 2005. "Testing for Weak Instruments in Linear IV Regression." In Identification and Inference for Econometric Models: Essays in Honor of Thomas Rothenberg. , ed. Donald W. K. Andrews and James H. Stock, 80-108. New York: Cambridge University Press.

Yu, Miaojie. 2015. "Processing Trade, Firms Productivity, and Tariff Reductions: Evidence from Chinese Products." The Economic Journal, 125(585): 943-988. 


\section{Appendix}

\section{A Derivations of Equation 13}

This Appendix is dedicated to derive the markup formula (13). Consider the following production function for firm $f$ in producing a product $h$ at time $t$ :

$$
Q_{f h t}=F_{t}\left(\boldsymbol{X}_{f h t}\right) \exp \left(\varphi_{f t}\right)
$$

where $Q_{f h t}$ is physical output and $\boldsymbol{X}_{f h t}$ is a vector of inputs. Recall the production function (2), this vector of inputs includes capital, labor and intermediate inputs. There are two assumptions made about productivity. First, productivity $\varphi$ enters in log-additive form and is Hicks-neutral. Second, we assume that productivity is firm-specific. The second assumption follows a tradition in the trade literature that combines firm-specific productivity with firm-product-specific demand shocks (e.g., see Bernard, Redding and Schott, 2010).

Producers minimize their production costs. Let $V_{f h t}$ denote the vector of variable inputs used to produce a product $h$. These inputs could be freely adjusted at any point in time. Moreover, we use the vector $K_{f h t}$ to denote dynamic inputs of production, which are any input that is subject to adjustment costs, for instance, capital. We consider the firm's cost function to be conditional on the set of dynamic inputs $K_{f h t}$. The associated Lagrangian function can be written as:

$$
\begin{aligned}
L\left(V_{f h t}, K_{f h t}, \lambda_{f h t}\right) & =\sum_{v=1}^{V} P_{f h t}^{v} V_{f h t}^{v}+\sum_{d=1}^{D} r_{f h t}^{d} K_{f h t}^{d} \\
& +\lambda_{f h t}\left[Q_{f h t}-Q_{f h t}\left(V_{f h t}, K_{f h t}, \varphi_{f t}\right)\right]
\end{aligned}
$$

where $P_{f h t}^{v}$ and $r_{f h t}^{d}$ denote the firm's input prices for the variable inputs $v=1, \ldots, V$ and for the dynamic inputs $d=1, \ldots, D$, respectively. The first order condition for any variable input that is free of adjustment costs yields:

$$
\frac{\partial L_{f h t}}{\partial V_{f h t}}=P_{f h t}^{v}-\lambda_{f h t} \frac{\partial Q_{f h t}(\cdot)}{\partial V_{f h t}}
$$

where the marginal cost of production at a given level of output is $\lambda_{f h t}$ since $\partial L_{f h t} / \partial Q_{f h t}=$ $\lambda_{f h t}$. Rearranging terms and multiplying both sides by $V_{f h t} / Q_{f h t}$ gives the following expression: 


$$
\frac{\partial Q_{f h t}(\cdot)}{\partial V_{f h t}} \frac{V_{f h t}}{Q_{f h t}}=\frac{1}{\lambda_{f h t}} \frac{P_{f h t}^{v} V_{f h t}}{Q_{f h t}}
$$

The left-hand side of the above equation represents the elasticity of output with respect to the variable input vector $V_{f h t}$ (the so called "output elasticity"). This approach requires only one freely adjustable input into the production process. Define the markup as $\mu_{f h t}=\ln \left(P_{f h t} / \lambda_{f h t}\right)$, where $P_{f h t}$ is the price for product $h$ produced by firm $f$ at time $t{ }^{43}$ As shown by De Loecker and Warzynski (2012) and De Loecker et al. (2016), the cost-minimization condition can be rearranged to obtain the following expression of markup for each product $h$ produced by firm $f$ at time $t$ :

$$
\mu_{f h t}=\ln \left(\theta_{f h t}^{v}\left(\alpha_{f h t}^{v}\right)^{-1}\right)
$$

\section{B Measure of revenue-based markup}

In order to estimate firm-level markups, we use NBSC's firm-level production survey data, which provides information on labor employment $l_{f t}$. We use the sales revenue as a measure of $q_{f t}$, the net value of fixed assets as a measure of $k_{f t}$ and the total value of intermediate materials as a measure of $m_{f t}$. To back out the physical quantity of $q_{f t}, k_{f t}$, and $m_{f t}$, we deflate these values with sector-specific price indices provided by Brandt, Van Biesebroeck and Zhang (2012).

We follow De Loecker and Warzynski (2012) in dealing with the unobserved productivity shocks $\varphi_{f t}$ in the production function, which are potentially correlated with input choices. As in Levinsohn and Petrin (2003), the firm's material demand depends on its capital stock $k_{f t}$ and productivity $\varphi_{f t}$ as well as other variables that could potentially affect the firm's choice of materials in vector $\boldsymbol{z}_{f t}$ :

$$
m_{f t}=m_{t}\left(k_{f t}, \varphi_{f t}, \boldsymbol{z}_{f t}\right)
$$

where $\boldsymbol{z}_{f t}$ include export status, input and output tariffs, 4-digit industry dummies, and city dummies. By assuming equation (B.4) is monotonic in $\varphi_{f t}$, we can invert this function to proxy for productivity shocks:

$$
\varphi_{f t}=h_{t}\left(k_{f t}, m_{f t}, \boldsymbol{z}_{f t}\right)
$$

Then, by replacing the productivity shocks $\varphi_{f t}$ with equation (B.5), we can rewrite

\footnotetext{
${ }^{43}$ Here we define markups in logarithm. This reason is to be consistent with our previous model setup. This treatment differs slightly from the definition of markups in De Loecker and Warzynski (2012).
} 
the production function as:

$$
q_{f t}=\phi\left(l_{f t}, k_{f t}, m_{f t}, \boldsymbol{z}_{f t}\right)+\epsilon_{f t}
$$

After approximating the function with a third-order polynomial in all its elements with the exception of industry dummies and region dummies, we add the industry dummies and region dummies linearly, and this yields an estimate of predicted output $\widehat{\phi}_{f t}$ by getting rid of unanticipated shocks and/or the measurement error $\varepsilon_{f t}$ in the first stage.

In the second stage, we estimate the vector of coefficients $\beta=\left(\beta_{l}, \beta_{m}, \beta_{k}, \beta_{l l}, \beta_{m m}, \beta_{k k}, \beta_{l m}, \beta_{l k}, \beta_{m k}\right)$ by relying on the law of motion for productivity. More precisely, for any particular vector $\beta$, we compute the corresponding productivity:

$$
\begin{aligned}
\varphi_{f t}(\beta)= & \widehat{\phi}_{f t}-\beta_{l} l_{f t}-\beta_{m} m_{f t}-\beta_{k} k_{f t}-\beta_{l l} l_{f t}^{2}-\beta_{m m} m_{f t}^{2} \\
& -\beta_{k k} k_{f t}^{2}-\beta_{l m} l_{f t} m_{f t}-\beta_{m k} m_{f t} k_{f t}-\beta_{k l} k_{f t} l_{f t}
\end{aligned}
$$

If we assume that productivity $\varphi_{f t}$ follows a Markov chain:

$$
\varphi_{f t}=g\left(\omega_{f t-1}, \tau_{f t-1}^{i n p u t}, \tau_{f t-1}^{i n p u t}, e_{f t-1}\right)+\xi_{f t},
$$

then we can recover the innovation to productivity given $\beta, \xi_{f t}(\beta)$, by regressing $\varphi_{f t}(\beta)$ on its lags. Note that $\xi_{f t}$ is a function of the chosen vector $\beta$. Moreover, this innovation term $\xi_{f t}(\beta)$, by definition, is independent of all lagged variables. In particular we have a set of moment conditions: ${ }^{44}$

$$
E\left(\xi_{f t} \mathbf{Y}_{f t}\right)=0
$$

where $\mathbf{Y}_{f t}$ contains lagged labor, current capital, lagged materials as well as lagged input/output tariffs, lagged export status, and their appropriate interactions with inputs. Equation (B.6) generates the moment conditions which allow us to estimate the vector of coefficients $\beta$. The firm-level markup is defined as $\widehat{\mu}_{f t}=\ln \left(\widehat{\theta}_{f t}^{M} \frac{P_{f t} Q_{f t}}{P_{f t}^{M} V_{f t}^{M}}\right)$, where $\widehat{\theta}_{f t}^{M}$ is the output elasticity for materials; $P_{f t} Q_{f t}$ is the total sales; $P_{f t}^{M} V_{f t}^{M}$ is the value of total input materials. The material output elasticity, $\widehat{\theta}_{f t}^{M}$, can be estimated as:

$$
\widehat{\theta}_{f t}^{M}=\widehat{\beta}_{m}+2 \widehat{\beta}_{m m} m_{f t}+\widehat{\beta}_{l m} l_{f t}+\widehat{\beta}_{m k} k_{f t}
$$

\footnotetext{
${ }^{44}$ Recall that, to estimate the firm-product markup, we need to solve numerically a system of equations which requires extra information such as the sales of each product as well as the input allocation across products.
} 


\section{Measure of quantity-based markup}

We combine NBSC's survey data with its physical-quantity dataset for the period 20002006. This merged data set contains physical quantities of output, which can be used as a measure of $q_{f t}$ to estimate markups. However, capital $k_{f t}$ and material $m_{f t}$ inputs are still only available in value terms. To back out physical quantities of $k_{f t}$ and $m_{f t}$, we still have deflate these values with sector-specific price indices provided by Brandt, Van Biesebroeck and Zhang (2012). As a result, there exist a deviation of the unobserved (log) firm-specific input price from the (log) industry-wide input price index. The true estimation specification of equation now becomes:

$$
q_{f t}=f\left(x_{f t} ; \beta\right)+B\left(\mathbf{w}_{f t} ; x_{f t} ; \beta\right)+\varphi_{f t}+\varepsilon_{f t}
$$

where $x_{f t}$ denotes the (observed) vector of deflated inputs; $\mathbf{w}_{f t}$ denotes the deviation of the unobserved (log) firm-specific input price from the (log) industry-wide input price index. Hence, consistently estimating the above equation requires a proper control for the unobserved firm productivity $\varphi_{f t}$ and the omitted firm-specific input price $B\left(\mathbf{w}_{f t} ; x_{f t} ; \beta\right)$.

To control for omitted firm-specific input prices, we follow De Loecker et al. (2016) and $\mathrm{Lu}$ and $\mathrm{Yu}(2015)$ by assuming that firm-specific input prices $\omega_{f t}$ are a function of output price $\left(p_{f t}\right)$, market share $\left(m s_{f t}\right)$, and exporter status $\left(e_{f t}\right)$, i.e., $\mathbf{w}_{f t}=w_{t}\left(p_{f t}, m s_{f t}, e_{f t}\right)$. The merged dataset built on the survey data and the quantity-output data enables us to calculate the output price $p_{f t}$. Now, $B_{f t}$ becomes $B\left(\left(p_{f t}, m s_{f t}, e_{f t}\right) \times\left(1, x_{f t}\right) ; \beta ; \delta\right)$, where $\delta$ corresponds to the parameters in $w_{t}(\cdot)$. ${ }^{45}$

As in Appendix B, we follow the method in Levinsohn and Petrin (2003) to proxy for productivity shocks by equation (B.5):

$$
\varphi_{f t}=h_{t}\left(k_{f t}, m_{f t}, \boldsymbol{z}_{f t}\right)
$$

where the vector $\boldsymbol{z}_{f t}$ include output price, market share, export status, input and output tariffs, product dummies, and city dummies.

Plugging the expressions for the input price correction and for the unobserved productivity into production function, we have:

$$
q_{f t}=\phi_{t}\left(x_{f t}, \mathbf{Z}_{f t}\right)+\varepsilon_{f t}
$$

\footnotetext{
${ }^{45}$ In our benchmark specifications, we only used the firm-level production survey data. This data set does not have physical quantities of output. Consequently, there is no information on output prices. This means that, when the survey data is used, we could not control the deviation of the unobserved (log) firm-specific input/output price from the (log) industry-wide input/output price index.
} 
As in Appendix B, we approximate the function with a third-order polynomial. This yields an estimate of predicted output $\widehat{\phi}_{f t}$ in the first stage.

In the second stage, we express productivity $\varphi_{f t}$ as a function of data and parameters:

$$
\varphi_{f t}(\beta)=\widehat{\phi}_{f t}-f\left(x_{f t} ; \beta\right)-B\left(\left(p_{f t}, m s_{f t}, e_{f t}\right) \times\left(1, x_{f t}\right) ; \beta ; \delta\right)
$$

To recover the parameter vectors $\beta$ and $\delta$ in the second stage, we consider the following law of motion for productivity:

$$
\varphi_{f t}=g\left(\varphi_{f t-1}, \tau_{f t-1}^{i n p u t}, \tau_{f t-1}^{i n p u t}, e_{f t-1}\right)+\xi_{f t}
$$

We form moments based on the innovation in productivity shock $\xi_{f t}$, which satisfies:

$$
\xi_{f t}=\varphi_{f t}-E\left(\varphi_{f t} \mid \varphi_{f t-1}, \tau_{f t-1}^{i n p u t}, \tau_{f t-1}^{\text {input }}, e_{f t-1}\right)
$$

The moments that are used to identify parameter vectors $\beta$ and $\delta$ are:

$$
E\left(\xi_{f t} \mathbf{Y}_{f t}\right)=0
$$

where $\mathbf{Y}_{f t}$ contains lagged labor, current capital, lagged materials, as well as lag output prices, lagged market shares, lagged input/output tariff, lagged export status, and their appropriate interactions with inputs. After we have estimated the parameters $\beta$ and $\delta$, we can recover input prices according to $\mathbf{w}_{f t}=w_{t}\left(p_{f t}, m s_{f t}, e_{f t}\right)$.

The quantity output dataset provides physical quantity information at the firmproduct level, but in this dataset products are defined more broadly than in the custom data. In other words, one product in the quantity-based dataset corresponds to several products at the HS 6-digit level. Therefore, although we consider single-product firms, when we merged the production data with the customs data, we will have multi-product firms. ${ }^{46}$ When we estimate the input cost share $\widehat{\rho}_{f h t}$ and the output elasticity for materials $\widehat{\theta}_{f h t}^{M}$, we also control for the estimated input prices as in De Loecker et al. (2016). Then we can compute the markup for each firm-product pair $(f, h)$ in each period $t$ using $\widehat{\mu}_{f h t}=\ln \left(\widehat{\theta}_{f h t}^{M} \frac{P_{f h t} Q_{f h t}}{\exp \left(\widehat{\rho}_{f h t}\right) P_{f t}^{M} V_{f t}^{M}}\right)$.

\footnotetext{
${ }^{46}$ Unfortunately, the quantity output dataset from NBSC does not provide information of sales value at the firm-product level. As a result, we can not calculate firm-product markups based on the merged data (built on NBSC's survey data and quantity output data). The reason for this inability is that we have no idea about the firm-product share of the input's expenditure $\alpha$.
} 


\section{Supplementary Tables}

Table A.1: Average Markup of Chinese Firms by Sector

\begin{tabular}{|c|c|c|c|c|c|c|c|c|c|c|}
\hline \multirow[t]{2}{*}{ Sector (2-digit CIC industry code) } & \multicolumn{5}{|c|}{ Ordinary trade } & \multicolumn{5}{|c|}{ Processing trade } \\
\hline & $(1)$ & $(2)$ & $(3)$ & $(4)$ & $(5)$ & $(6)$ & $(7)$ & $(8)$ & (9) & $(10)$ \\
\hline Processing of Food from Agricultural Pro & 2.585 & 1.875 & 2.341 & 1.880 & 1.285 & 1.886 & 1.575 & 1.818 & 1.570 & 1.239 \\
\hline Foods (14) & 2.519 & 1.647 & 2.154 & 1.782 & 1.331 & 1.945 & 1.588 & 1.798 & 1.580 & 1.266 \\
\hline Beverages (15) & 4.566 & 1.942 & 2.932 & 1.854 & 1.397 & 2.450 & 1.534 & 1.635 & 1.565 & 1.314 \\
\hline Textile (17) & 2.647 & 1.953 & 2.448 & 1.964 & 1.361 & 2.270 & 1.932 & 2.204 & 1.722 & 1.351 \\
\hline Wearing Apparel, Footware, and Caps & 1.939 & 0.677 & 1.816 & 1.672 & 1.294 & 1.774 & 0.634 & 1.638 & 1.560 & 1.256 \\
\hline Leather, Fur, Feather and Related Pro & 2.664 & 0.896 & 1.798 & 1.891 & 1.348 & 2.265 & 1.057 & 1.833 & 1.657 & 1.300 \\
\hline $\begin{array}{l}\text { Processing of Timber, Manufacture of Wood, Bamboo, } \\
\text { Rattan, Palm, and Straw Products (20) }\end{array}$ & 3.684 & 2.205 & 2.127 & 2.426 & 1.404 & 3.023 & 2.118 & 2.147 & 1.935 & 1.382 \\
\hline Furniture (21) & 4.941 & 2.607 & 2.950 & 2.724 & 1.858 & 4.533 & 2.805 & 3.311 & 2.674 & 1.885 \\
\hline & 4.766 & 2.132 & 2.207 & 2.792 & 1.410 & 3.486 & 1.995 & 2.223 & 2.061 & 1.401 \\
\hline Printing, I & 3.857 & 3.138 & 3.012 & 2.216 & 1.505 & 1.878 & 2.610 & 2.130 & 1.536 & 1.497 \\
\hline Articles Fo & 5.040 & 2.490 & 3.122 & 2.561 & 1.637 & 3.947 & 2.419 & 2.808 & 2.401 & 1.732 \\
\hline Pet & 3.055 & 1.575 & 2.971 & 2.700 & 1.692 & 2.403 & 1.339 & 1.719 & $\mathrm{~N} / \mathrm{A}$ & 1.592 \\
\hline Raw & 2.927 & 2.353 & 2.412 & 2.549 & 1.451 & 2.395 & 1.932 & 1.989 & 2.277 & 1.465 \\
\hline & 4.044 & 2.673 & 2.628 & 2.518 & 1.402 & 2.716 & 3.106 & 1.959 & 2.326 & 1.387 \\
\hline Che & 2.343 & 1.222 & 1.976 & 1.659 & 1.387 & 2.312 & 1.536 & 1.981 & 1.519 & 1.384 \\
\hline & & 2.533 & 2.711 & 2.396 & 1.378 & 3.026 & 2.412 & 2.437 & 2.145 & 74 \\
\hline & 2.430 & 2.656 & 3.194 & 1.725 & 1.458 & 2.225 & 2.567 & 2.691 & 1.661 & 1.478 \\
\hline Non-r & 4.574 & 1.775 & 2.463 & 2.514 & 1.749 & 2.906 & 1.991 & 2.246 & 2.090 & 1.740 \\
\hline $\mathrm{Sm}$ & 3.479 & 2.051 & 1.919 & 1.324 & 1.425 & 2.473 & 1.549 & 1.590 & 1.533 & 1.446 \\
\hline Smelting a & 2.055 & 1.653 & 1.678 & 1.166 & 1.442 & 1.669 & 1.732 & 1.633 & 1.488 & 1.438 \\
\hline & & 1.963 & 2.216 & 2.530 & 1.517 & 2.928 & 1.822 & 1.977 & 2.136 & 1.507 \\
\hline General & 4.355 & 2.132 & 2.662 & 2.455 & 1.449 & 3.239 & 2.041 & 2.355 & 2.037 & 1.474 \\
\hline Special Pu & 4.579 & 2.436 & 3.129 & 2.919 & 1.476 & 3.286 & 2.190 & 2.680 & 2.282 & 1.529 \\
\hline Transport E & 3.347 & 2.097 & 3.196 & 2.022 & 1.470 & 2.716 & 2.000 & 2.534 & 1.817 & 1.457 \\
\hline Electrical M & 3.711 & 2.325 & 2.100 & 2.411 & 1.740 & 3.131 & 2.146 & 2.143 & 1.940 & 1.821 \\
\hline $\begin{array}{c}\text { Communication Equipment, Computers and } \\
\text { Other Electronic Equipment (40) }\end{array}$ & 7.060 & 2.732 & 3.600 & 3.348 & 1.753 & 3.521 & 2.112 & 2.972 & 2.109 & 1.845 \\
\hline $\begin{array}{l}\text { Measuring Instruments and Machinery for } \\
\text { Cultural Activity and Office Work (41) }\end{array}$ & 4.90 & 2.716 & 3.077 & 2.702 & 1.658 & 3.945 & 2.502 & 2.833 & 2.449 & 663 \\
\hline Artwork and Other Manufacturing (42) & 2.600 & 1.993 & 2.020 & 1.824 & 1.540 & 2.399 & 2.043 & 2.102 & 1.797 & 1.549 \\
\hline
\end{tabular}

Notes: This table displays the average firm-product markup by 2-digit CIC sector for the sample of ordinary trade firms and the sample of processing trade firms during 2000-2006. Specifications 1-5 refer to ordinary trades, and specifications 6-10 refer to processing trades. In columns 1 and 6 we report the average firm-product markup used in our benchmark; in other columns we report the average firm-product markup used as robustness checks in section 5.3. In columns 2 and 7 we take advantage of our quantity-based dataset; in columns 3 and 8 we alter the production function by allowing the triple interaction term of labor, materials, and capital; in columns 4 and 9 we limit our sample to include only pure exporters; in columns 5 and 10 we estimate the markup based on our own model that requires only observable market shares and substitution elasticities. We trim observations with markup lower than the 5 th percentile or higher than the 95th percentile for each year. 
Table A.2: The Effect of Tariffs on Markups: Decomposition

\begin{tabular}{|c|c|c|c|c|c|c|c|c|}
\hline \multirow[t]{3}{*}{ Dependent variable: } & \multicolumn{4}{|c|}{ Firm-product-level $\theta$} & \multicolumn{4}{|c|}{ Firm-product-level $\alpha$} \\
\hline & (1) & $(2)$ & (3) & (4) & (5) & (6) & $(7)$ & (8) \\
\hline & \multicolumn{2}{|c|}{ Ordinary Trade } & \multicolumn{2}{|c|}{ Processing Trade } & \multicolumn{2}{|c|}{ Ordinary Trade } & \multicolumn{2}{|c|}{ Processing Trade } \\
\hline \multirow[t]{2}{*}{ Input tariff } & $-0.251^{* * *}$ & $-0.217^{* *}$ & -0.037 & 0.102 & $2.561^{* *}$ & $2.174^{*}$ & -0.205 & -0.446 \\
\hline & $(0.096)$ & $(0.090)$ & $(0.142)$ & $(0.136)$ & $(1.185)$ & $(1.147)$ & $(1.944)$ & $(1.751)$ \\
\hline \multirow[t]{2}{*}{ Output tariff } & -0.034 & -0.011 & -0.080 & -0.089 & -0.936 & -0.769 & 1.607 & 1.366 \\
\hline & $(0.073)$ & $(0.075)$ & $(0.122)$ & $(0.119)$ & $(0.848)$ & $(0.821)$ & $(2.126)$ & $(1.890)$ \\
\hline \multirow[t]{2}{*}{$\log (\mathrm{TFP})$} & & 0.001 & & 0.012 & & $-0.942^{* * *}$ & & $-0.936^{* * *}$ \\
\hline & & $(0.011)$ & & $(0.010)$ & & $(0.062)$ & & $(0.054)$ \\
\hline Other Firm-level controls & NO & YES & NO & YES & NO & YES & NO & YES \\
\hline Industry-level controls & $\mathrm{NO}$ & YES & $\mathrm{NO}$ & YES & NO & YES & NO & YES \\
\hline Year Fixed Effect & YES & YES & YES & YES & YES & YES & YES & YES \\
\hline Industry Fixed Effect & YES & YES & YES & YES & YES & YES & YES & YES \\
\hline Firm-Product Fixed Effect & YES & YES & YES & YES & YES & YES & YES & YES \\
\hline Observations & 575824 & 575824 & 168813 & 168813 & 575836 & 575836 & 168813 & 168813 \\
\hline R-squared & 0.974 & 0.975 & 0.938 & 0.942 & 0.873 & 0.874 & 0.856 & 0.858 \\
\hline
\end{tabular}

Notes: ${ }^{* *} \mathrm{p}<0.01,{ }^{* *} \mathrm{p}<0.05,{ }^{*} \mathrm{p}<0.1$. Robust standard errors corrected by clustering variables at the industry-year level are in parentheses. Specifications 1-2 and 5-6 use ordinary trade observations, and specifications 3-4 and 7-8 use processing trade observations. Specifications 1-4 adopt firm-product-level markups with export quantity projection, and specifications 5-8 adopt firm-level markups. Other firm-level controls include firm size measured by employment, capital-labor ratio, and average wage; industry-level controls include industry average wage, capital intensity, share of college-trained employees, and the Herfindahl index at the 4digit CIC industry level. 
Table A.3: The Effect of Tariffs on Alternative Markups by Import Dependence

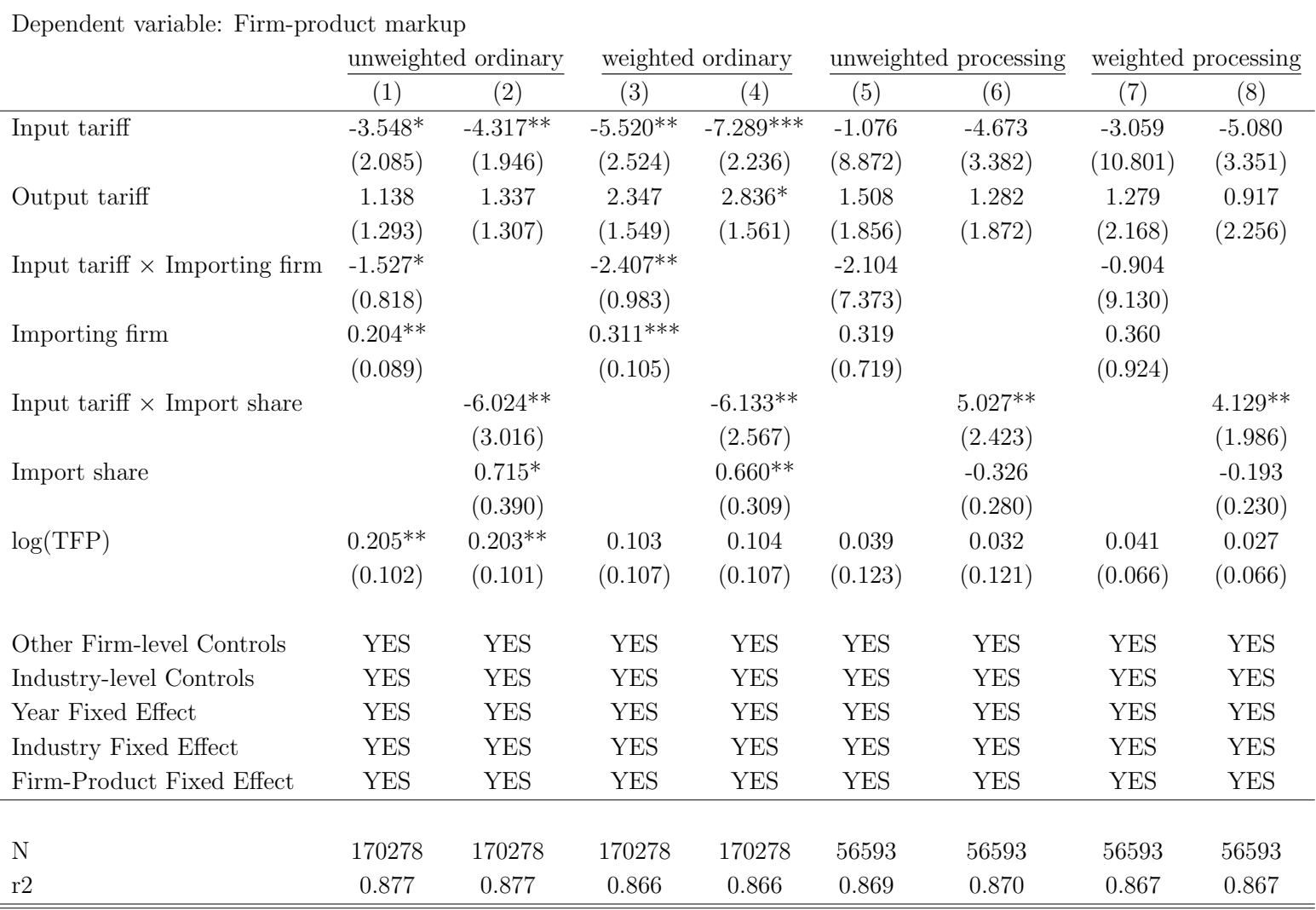

Notes: ${ }^{* * *} \mathrm{p}<0.01,{ }^{* *} \mathrm{p}<0.05,{ }^{*} \mathrm{p}<0.1$. Robust standard errors corrected by clustering variables at the industryyear level are in parentheses. Specifications 1-4 refer to ordinary trades, and specifications 5-8 refer to processing trades. In columns 1-2 and 5-6 we run unweighted regressions, and in columns 3-4 and 7-8 we run regression weighted by the number of observations in the 2-digit CIC industry. Other firm-level controls include firm size measured by employment, capital-labor ratio, and average wage; industry-level controls include industry average wage, capital intensity, share of college-trained employees, and the Herfindahl index at the 4-digit CIC industry level. The results stay unchanged when we exclude firm-level and industry-level controls. 
Table A.4: The Effect of Tariffs on Alternative Markups by Marginal Costs

Dependent variable: Firm-product marginal costs (1-2 and 5-6); Firm-product markups (3-4 and 7-8)

\begin{tabular}{|c|c|c|c|c|c|c|c|c|}
\hline & \multicolumn{4}{|c|}{ Sample of Ordinary Trade } & \multicolumn{4}{|c|}{ Sample of Processing Trade } \\
\hline & (1) & $(2)$ & $(3)$ & (4) & (5) & (6) & (7) & (8) \\
\hline & \multicolumn{2}{|c|}{ marginal cost } & \multicolumn{2}{|c|}{ markup } & \multicolumn{2}{|c|}{ marginal cost } & \multicolumn{2}{|c|}{ markup } \\
\hline \multirow[t]{2}{*}{ Input tariff } & $4.096^{* *}$ & $4.226^{* *}$ & -0.636 & -0.616 & 2.657 & 2.747 & -0.561 & -0.517 \\
\hline & $(1.935)$ & $(1.915)$ & $(0.792)$ & $(0.783)$ & $(3.149)$ & $(3.204)$ & $(0.640)$ & $(0.644)$ \\
\hline \multirow[t]{2}{*}{ Output tariff } & -1.543 & -1.251 & -0.020 & -0.058 & -1.066 & -0.901 & $0.777^{*}$ & 0.639 \\
\hline & $(1.261)$ & $(1.351)$ & $(0.423)$ & $(0.451)$ & $(1.725)$ & $(1.861)$ & $(0.433)$ & $(0.398)$ \\
\hline \multirow[t]{2}{*}{ marginal cost } & & & $-0.984^{* * *}$ & $-0.984^{* * *}$ & & & $-0.981^{* * *}$ & $-0.981^{* * *}$ \\
\hline & & & $(0.005)$ & $(0.005)$ & & & $(0.005)$ & $(0.004)$ \\
\hline \multirow[t]{2}{*}{$\log (\mathrm{TFP})$} & & $-0.207^{* *}$ & & 0.002 & & -0.051 & & -0.011 \\
\hline & & $(0.100)$ & & $(0.012)$ & & $(0.123)$ & & $(0.011)$ \\
\hline Other Firm-level Controls & NO & YES & $\mathrm{NO}$ & YES & $\mathrm{NO}$ & YES & $\mathrm{NO}$ & YES \\
\hline Industry-level Controls & $\mathrm{NO}$ & YES & $\mathrm{NO}$ & YES & $\mathrm{NO}$ & YES & NO & YES \\
\hline Year Fixed Effect & YES & YES & YES & YES & YES & YES & YES & YES \\
\hline Industry Fixed Effect & YES & YES & YES & YES & YES & YES & YES & YES \\
\hline Firm-Product Fixed Effect & YES & YES & YES & YES & YES & YES & YES & YES \\
\hline Observations & 170278 & 170278 & 170278 & 170278 & 56593 & 56593 & 56593 & 56593 \\
\hline R-squared & 0.887 & 0.887 & 0.985 & 0.985 & 0.900 & 0.900 & 0.991 & 0.991 \\
\hline
\end{tabular}

Notes: ${ }^{* * *} \mathrm{p}<0.01,{ }^{* *} \mathrm{p}<0.05,{ }^{*} \mathrm{p}<0.1$. Robust standard errors corrected by clustering variables at the industryyear level are in parentheses. Specifications 1-4 refer to ordinary trades, and specifications 5-8 refer to processing trades. In columns 1-2 and 5-6 the dependent variables are firm-product level marginal costs; in columns 3-4 and 7-8 the dependent variables are firm-product level markups. Other firm-level controls include firm size measured by employment, capital-labor ratio, and average wage; industry-level controls include industry average wage, capital intensity, share of college-trained employees, and the Herfindahl index at the 4-digit CIC industry level. 
Table A.5: Model-Based Markup Measures

Dependent variable: Firm-product markup

\begin{tabular}{|c|c|c|c|c|c|c|c|c|}
\hline & \multicolumn{4}{|c|}{ Alternative Market Share } & \multicolumn{4}{|c|}{$\sigma=6$} \\
\hline & (1) & $(2)$ & (3) & (4) & (5) & (6) & (7) & (8) \\
\hline & \multicolumn{2}{|c|}{ Ordinary trade } & \multicolumn{2}{|c|}{ Processing trade } & \multicolumn{2}{|c|}{ Ordinary trade } & \multicolumn{2}{|c|}{ Processing trade } \\
\hline Input tariff & $\begin{array}{c}-0.009 * * * \\
(0.003)\end{array}$ & $\begin{array}{c}-0.010^{* * *} \\
(0.003)\end{array}$ & $\begin{array}{l}-0.002 \\
(0.008)\end{array}$ & $\begin{array}{l}-0.002 \\
(0.008)\end{array}$ & $\begin{array}{c}-0.090^{* * *} \\
(0.025)\end{array}$ & $\begin{array}{c}-0.087^{* * *} \\
(0.026)\end{array}$ & $\begin{array}{l}-0.043 \\
(0.056)\end{array}$ & $\begin{array}{l}-0.041 \\
(0.057)\end{array}$ \\
\hline Output tariff & $\begin{array}{c}0.005 * * \\
(0.002)\end{array}$ & $\begin{array}{c}0.005^{* *} \\
(0.002)\end{array}$ & $\begin{array}{c}0.008 \\
(0.005)\end{array}$ & $\begin{array}{c}0.008 \\
(0.005)\end{array}$ & $\begin{array}{c}0.005 \\
(0.015)\end{array}$ & $\begin{array}{c}0.005 \\
(0.015)\end{array}$ & $\begin{array}{l}-0.030 \\
(0.035)\end{array}$ & $\begin{array}{l}-0.037 \\
(0.035)\end{array}$ \\
\hline $\log (\mathrm{TFP})$ & & $\begin{array}{l}-0.000 \\
(0.000)\end{array}$ & & $\begin{array}{c}0.001 \\
(0.000)\end{array}$ & & $\begin{array}{c}0.002^{* *} \\
(0.001)\end{array}$ & & $\begin{array}{l}-0.002 \\
(0.003)\end{array}$ \\
\hline Other Firm-level Controls & $\mathrm{NO}$ & YES & NO & YES & NO & YES & NO & YES \\
\hline Industry-level Controls & NO & YES & $\mathrm{NO}$ & YES & $\mathrm{NO}$ & YES & NO & YES \\
\hline Year Fixed Effect & YES & YES & YES & YES & YES & YES & YES & YES \\
\hline Industry Fixed Effect & YES & YES & YES & YES & YES & YES & YES & YES \\
\hline Firm-Product Fixed Effect & YES & YES & YES & YES & YES & YES & YES & YES \\
\hline Observations & 575836 & 575836 & 168795 & 168795 & 575441 & 575441 & 167995 & 167995 \\
\hline R-squared & 0.999 & 0.999 & 0.997 & 0.997 & 0.707 & 0.707 & 0.722 & 0.722 \\
\hline
\end{tabular}

